\title{
Obstetric ultrasound use in low and middle income countries: a narrative review
}

\author{
Eunsoo Timothy Kim ${ }^{1,2}$, Kavita Singh ${ }^{1,3^{*}}$ (D), Allisyn Moran ${ }^{4}$, Deborah Armbruster ${ }^{4}$ and Naoko Kozuki ${ }^{5,6}$
}

\begin{abstract}
Introduction: Although growing, evidence on the impact, access, utility, effectiveness, and cost-benefit of obstetric ultrasound in resource-constrained settings is still somewhat limited. Hence, questions around the purpose and the intended benefit as well as potential challenges across various domains must be carefully reviewed prior to implementation and scale-up of obstetric ultrasound technology in low-and middle-income countries (LMICS).

Main Body: This narrative review discusses these issues for those trying to implement or scale-up ultrasound technology in LMICs. Issues addressed in this review include health personnel capacity, maintenance, cost, overuse and misuse of ultrasound, miscommunication between the providers and patients, patient diagnosis and care management, health outcomes, patient perceptions and concerns about fetal sex determination.

Conclusion: As cost of obstetric ultrasound becomes more affordable in LMICs, it is essential to assess the benefits, trade-offs and potential drawbacks of large-scale implementation. Additionally, there is a need to more clearly identify the capabilities and the limitations of ultrasound, particularly within the context of limited training of providers, to ensure that the purpose for which an ultrasound is intended is actually feasible. We found evidence of obstetric uses of ultrasound improving patient management. However, there was evidence that ultrasound use is not associated with reducing maternal, perinatal or neonatal mortality. Patients in various studies reported to have both positive and negative perceptions and experiences related to ultrasound and lastly, illegal use of ultrasound for determining fetal sex was raised as a concern.
\end{abstract}

\section{Plain English summary}

Prior to the implementation and scale-up of obstetric ultrasound technology in low- and middle-income countries, questions around the purpose, intended benefit, potential trade-offs and challenges must be carefully reviewed. This review paper focuses on issues around health personnel capacity, maintenance, cost, misuse and overuse, miscommunication between patients and providers, patient diagnosis and case management, health outcomes, perceptions and concerns about fetal sex determination.

We conclude that it is essential to assess the benefits, trade-offs and potential drawbacks of large-scale implementation as cost of obstetric ultrasound becomes more affordable in low- and middle-income countries. Additionally, there is a need to more clearly identify the capabilities and the limitations of ultrasound, particularly within the context of limited training of providers, to ensure that the purpose for which an ultrasound is intended is actually feasible. We found evidence of obstetric uses of ultrasound improving patient management. However, there was evidence that ultrasound use is not associated with reducing maternal, perinatal or neonatal mortality. Patients in various studies reported to have both positive and negative perceptions and experiences related to ultrasound and lastly, illegal use of ultrasound for determining fetal sex was raised as a concern.

\section{Background}

'Department of Maternal and Child Health, Gillings School of Global Public
Correspondence: kavita_singh@unc.edu Health, University of North Carolina at Chapel Hill, 135 Dauer Dr, Chapel Hill, NC 27516, USA

${ }^{3}$ MEASURE Evaluation, Carolina Population Center, University of North Carolina at Chapel Hill, Carolina Square, Suite 330, 123 West Franklin St, Chapel Hill, NC 27516, USA

Full list of author information is available at the end of the article
There are numerous applications and indications for ultrasound in low- and middle-income countries (LMICs). Ultrasound has been used to diagnose obstructed labor, non-cephalic presentation, single or multiple pregnancy, incomplete miscarriage, molar pregnancy, ectopic pregnancy, 
fetal abnormality, intrauterine growth restriction and placenta previa [1-5]. It has also been used to measure pelvic outlet and estimate gestational age [5-7]. Although the degree of diagnostic accuracy may vary depending on when pregnant women present themselves for an ultrasound exam [7], its utility has been highlighted in many studies nonetheless. Accurate assessment of gestational age for example is useful in distinguishing pre-term newborns from newborns who are low birth weight (but not pre-term), which is important because the needed interventions may differ [8].

In LMICs, ultrasound is mainly used to diagnose obstetric conditions [7, 9]. However, gynecological conditions have also been evaluated by ultrasound as well, particularly in emergency medicine $[9,10]$. Kotlyar and Moore stated that $53 \%$ of ultrasound scans were performed either for obstetric or gynecological conditions in a single center study from Monrovia, Liberia [11]. In another study in Cameroon, ultrasound determined that $33 \%$ of patients had gynecological conditions and 15\% had obstetric conditions [12]. Applications of ultrasound also extend to abdominal, musculoskeletal, cardiac, renal, pulmonary, trauma and soft tissue and vascular conditions $[3,7,10,13,14]$ as well as HIV, tuberculosis, intussusception, Wilms' tumor, Burkitt's lymphoma, hepatitis C, Chagas' disease, filariasis, myiasis and other protozoal, helminthic, viral and bacterial infections [7, 9]. For example, a trial in Rwanda reported that due to the high prevalence of HIV related cardiomyopathies, TB-related pericardial effusions and rheumatic disease, cardiac applications of ultrasound were frequently used [14]. In Botswana, most of the disease burden at the district level public hospitals are obstetric-related, followed by gynecological conditions and hepato-biliary conditions [4]. In Sudan where the prevalence of schistosomiasis is high, applications of ultrasound were highest for liver and spleen disorders, followed by obstetric conditions [15]. As evidenced by past studies, applications of ultrasound use are diversified based on geographic and disease context. Such high adoptability and wide ranging applications of ultrasound make it suitable for use in LMICs.

In recent years, portable ultrasound machines have become increasingly popular in LMICs due to their affordability, user-friendliness and adoptability to the harsh and restrictive conditions of resource-poor settings $[3,6,7,10,16,17]$. For example, newer ultrasound models are hand-held or hand-carried [17], and the price has significantly decreased compared to that of full-size ultrasound machines [3]. The interface software on these devices have also been simplified and streamlined [6] so that they may be used more broadly by different cadres of health workers, who have different capabilities [10]. As newer generations of ultrasound are becoming more suitable for LMICs, manufacturers could be looking to expand their markets and local healthcare staff may be weighing the benefits and disadvantages of introducing these newer ultrasound models into their facilities. Multilateral and bilateral organizations as well as private donors, therefore, may want to comprehensively assess the feasibility of introducing ultrasound in these settings before appropriating funds.

Although growing, evidence on the access, utility, effectiveness, and cost-benefit of obstetric ultrasound in resource-constrained settings is still somewhat limited $[5,18]$. It is also important to note that there is no evidence of its impact on reducing maternal or perinatal mortality $[9,19,20]$. Hence, questions around the purpose and the intended benefit as well as potential challenges across various domains must be carefully reviewed prior to implementation and scale-up of obstetric ultrasound technology in LMICs.

This narrative review discusses these issues for those trying to implement or scale-up ultrasound technology in LMICs. Issues addressed in this review include health personnel capacity, maintenance, cost, overuse and misuse of ultrasound, miscommunication between the providers and patients, patient diagnosis and care management, health outcomes, patient perceptions and concerns about fetal sex determination. Because obstetric conditions are the most common indication for ultrasound in LMICs [7, 9], this review mainly focuses on obstetric uses of ultrasound.

\section{Methods}

The existing literature on the use of ultrasound in LMICs was reviewed. The initial search was focused only on published review articles because of the short timeframe (May 3rd - August 2nd, 2016) in which to prepare for a Technical Consultation Meeting on Ultrasound Use in Lowand Middle-Income Countries which was held in Washington D.C. on August 2nd, 2016. This narrative review was initially prepared for the Technical Consultation Meeting in Washington D.C. but was later expanded to include additional articles.

Published review articles were searched in the following databases: PubMed, Global Health, CINAHL, Web of Science and Embase. Exact search terms and filters for the review articles are included in the Appendix. The initial database search returned a total of 391 articles and 6 review articles were retained for the literature review. After the initial electronic database search, 59 additional relevant articles and grey literature publications were identified through manual reference and Google searches. In this paper, data are synthesized from 65 sources (See Fig. 1).

Summary tables are presented for articles/studies in the review (See Tables 1, 2 and 3). Study quality was assessed using the following criteria: 1) study design randomized or non-randomized; 2) presence of a control 


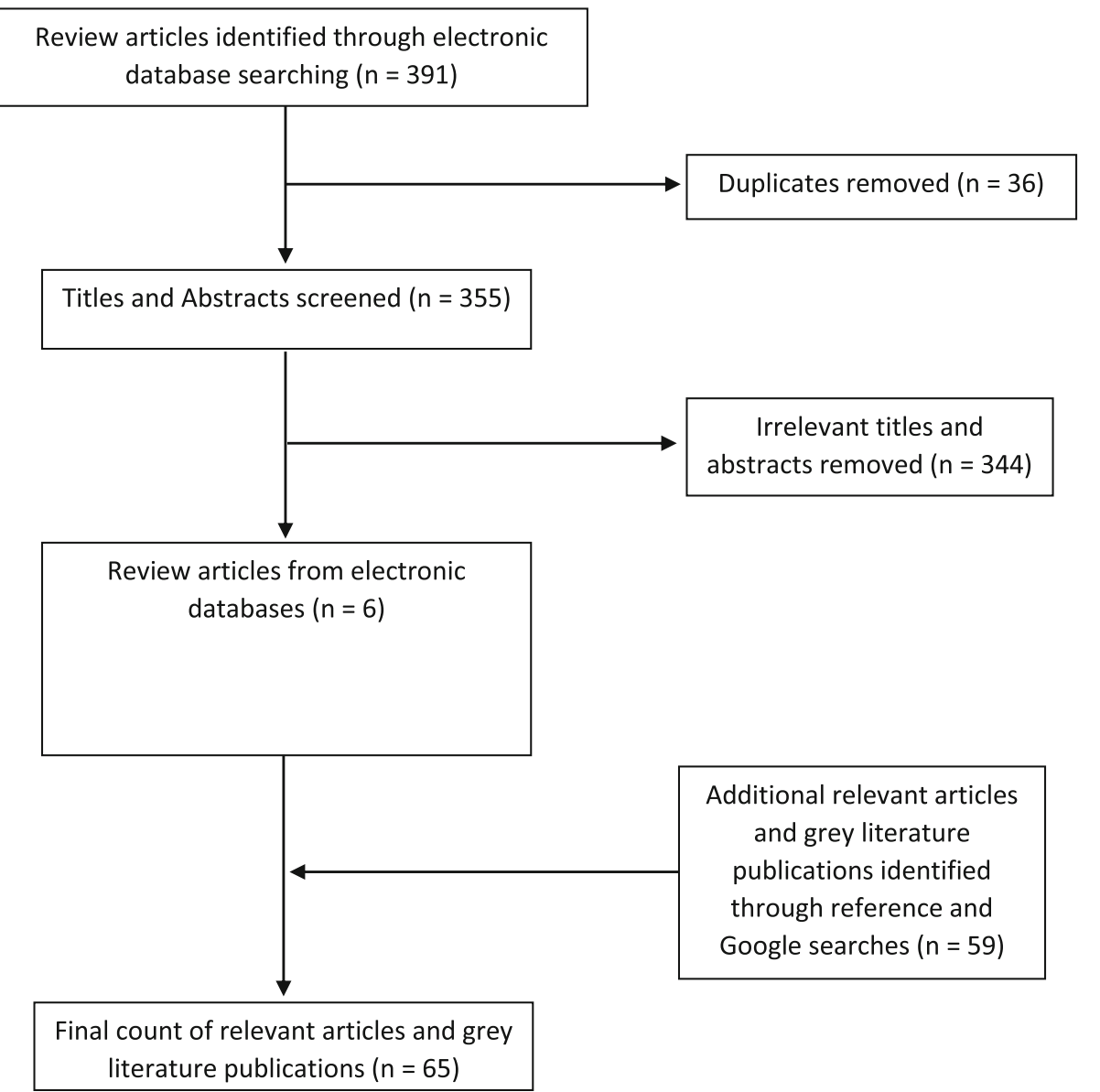

Fig. 1 Flowchart of search results

group. Information about the study location, study period, study description, key points, sample size, funding support and type of ultrasound machine are also presented. Qualitative studies or studies from which anecdotal accounts were retrieved were not included.

\section{Findings}

What are the effects of obstetric ultrasound? Care utilization and mortality

A recent cluster-randomized trial in Pakistan, Kenya, Zambia, the Democratic Republic of the Congo and Guatemala looked at the effects of antenatal ultrasound use in rural health center settings [20,21]. After stratifying by country, each of the intervention and comparison clusters were defined as a catchment area of a health center that records about 500 births every year [21]. Pregnant women in the intervention clusters were generally offered two antenatal ultrasound examinations, first exam between 18 and 22 weeks and the second exam between 32 and 36 weeks, and those with identified complications were referred to higher-level health facilities [21]. At the first visit, gestational age was determined and fetal number and position, cervical length, potential amniotic fluid abnormalities and potential congenital abnormalities were examined [21]. At the second visit, placental location and growth were observed in addition to all of the checks performed during the first visit [21]. The intervention package also included health worker training for antenatal ultrasound, emergency obstetric and neonatal care training at higher-level referral facilities and community sensitization events where people were informed about the diagnostic capabilities of ultrasound as well as the antenatal ultrasound services being offered at intervention facilities [21]. This recent study including five countries with a rigorous cluster-randomized design found no difference in intervention and comparison clusters in terms of antenatal care use, facility delivery, stillbirth rate, neonatal mortality and maternal mortality [20].

Another randomized study conducted in South Africa found that routine second-trimester ultrasound scanning did not result in a significant difference in perinatal mortality between the ultrasound scan group and the control group, 4.3 and $4.1 \%$ respectively with a relative risk of 1.05 and $95 \%$ confidence interval between 0.54 and 2.03 $[9,19]$. However, the study also noted that it had low 


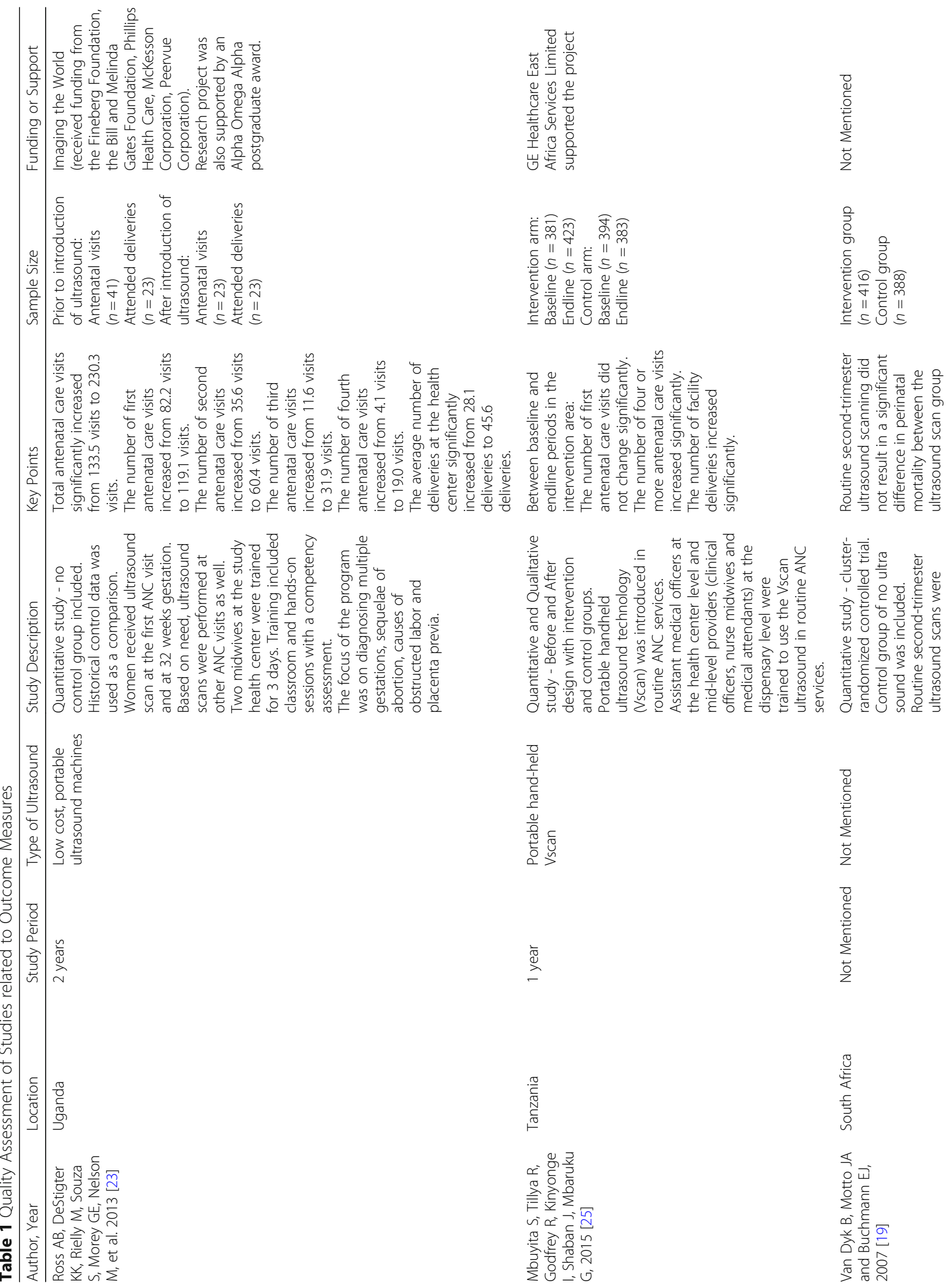




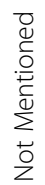

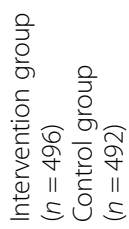

을 $\frac{\stackrel{2}{n}}{n}$

के 选

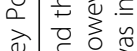

产

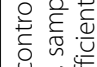

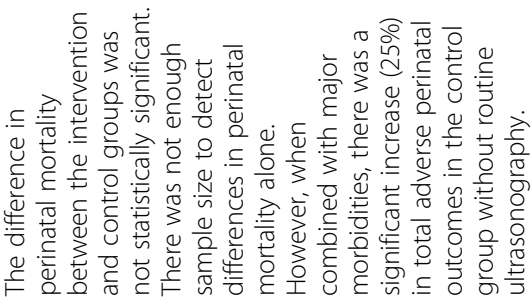

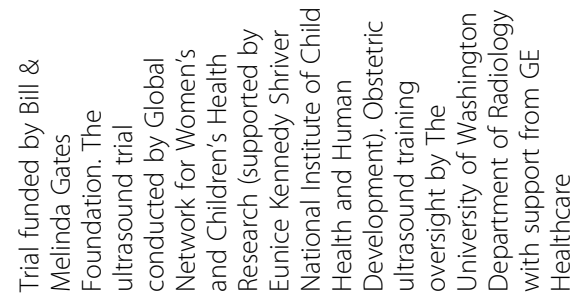

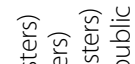

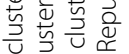

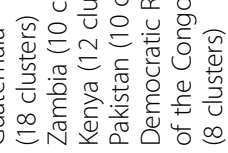

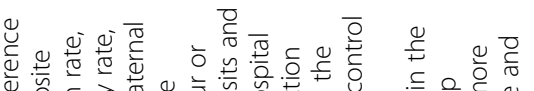

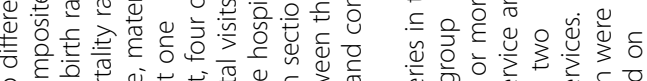

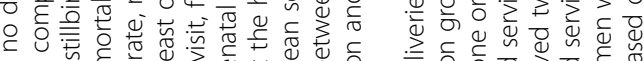

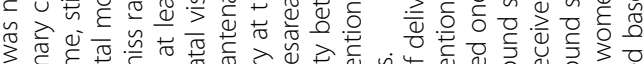

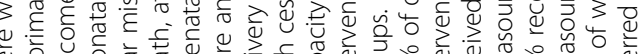
卢.

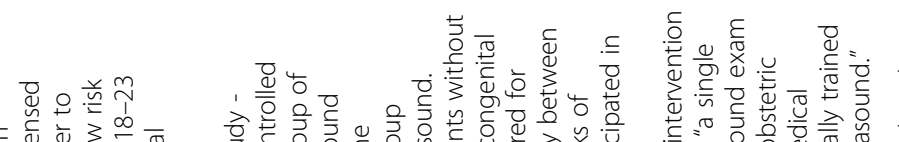

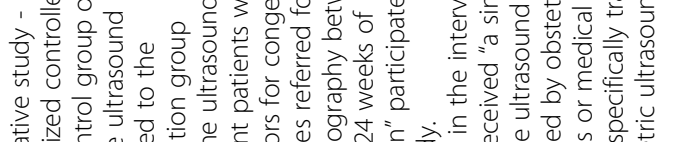

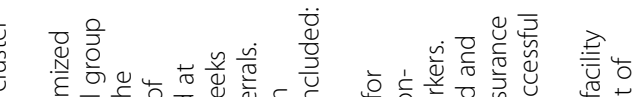
$1 \quad 0$

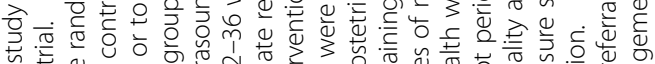

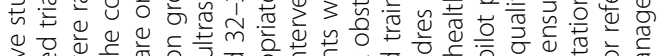

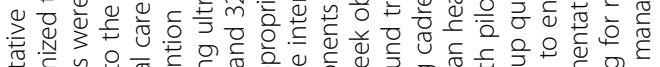

든

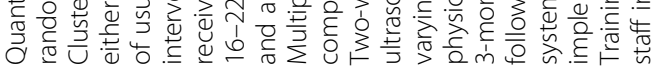

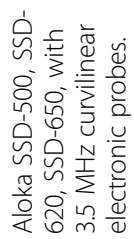

讨

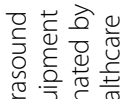

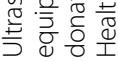

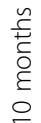

$\stackrel{n}{+}$
$\stackrel{2}{D}$
$\stackrel{\underline{\varepsilon}}{\infty}$

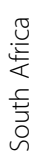

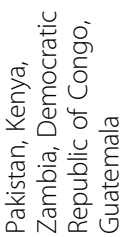

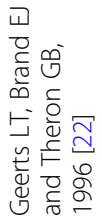

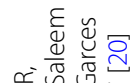

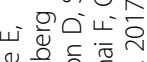

凹

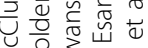




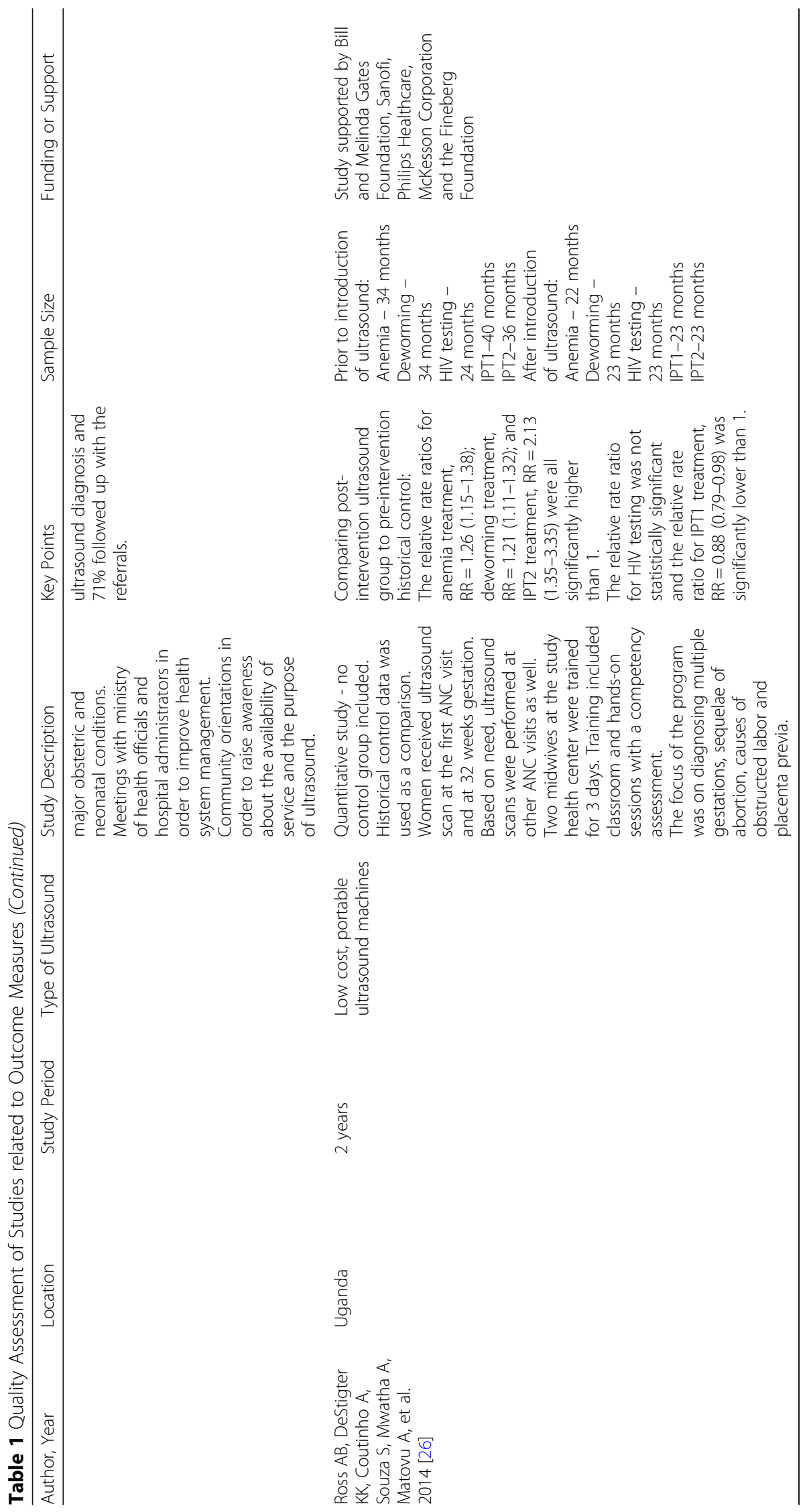




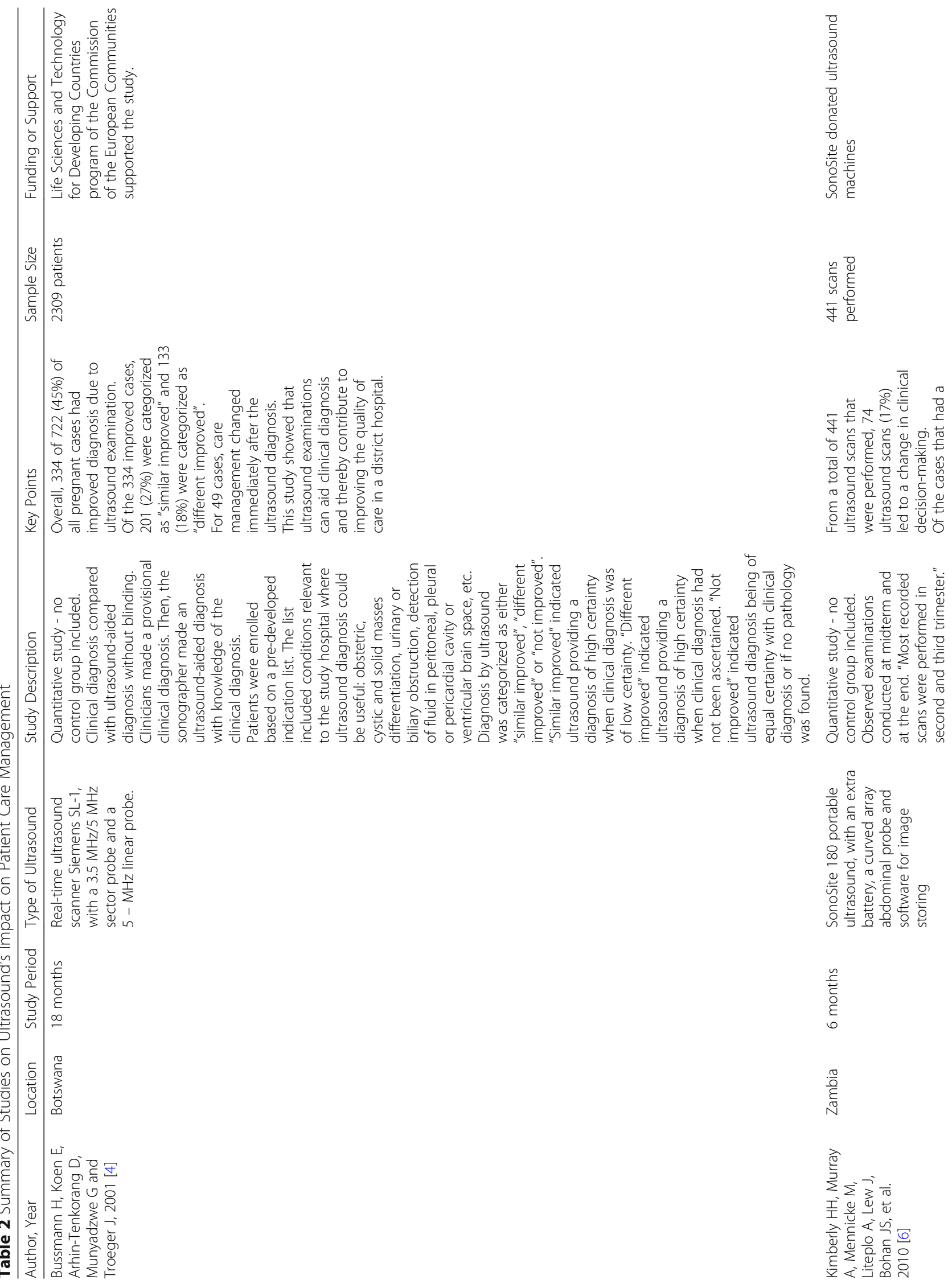




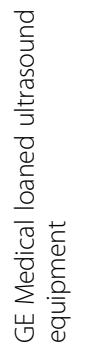

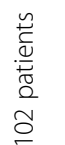

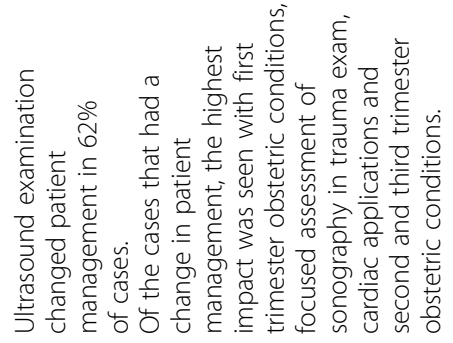

0
0
0
0
$\stackrel{0}{0}$
$\sum_{0}^{0}$
0
$\frac{0}{2}$

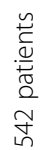

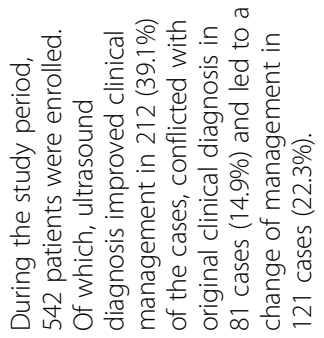

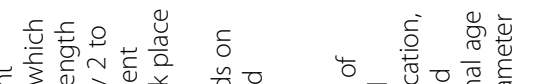

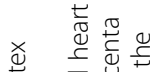

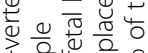

ত 은

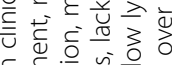

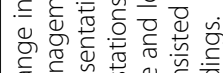

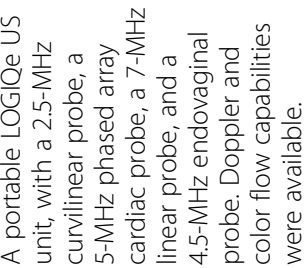

$\frac{\sqrt{2}}{\frac{1}{4}}$

$\frac{0}{\frac{0}{\bar{\alpha}}}$

$\stackrel{\frac{0}{\partial}}{\stackrel{0}{2}}$

등

잉

ํํำ
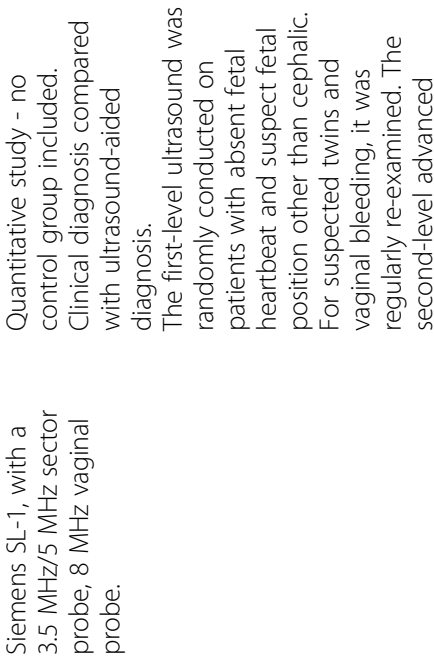

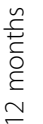

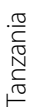

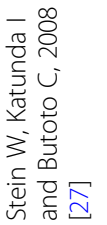




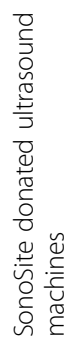

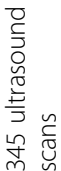

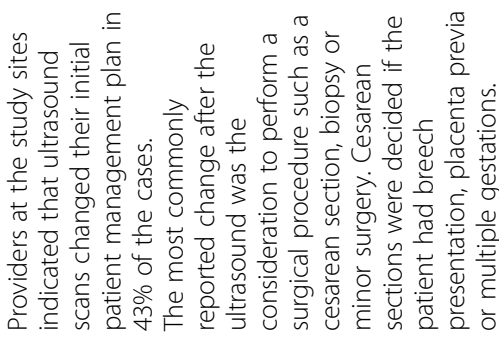

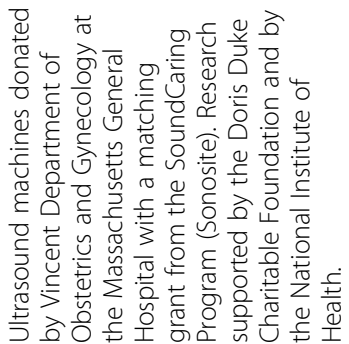

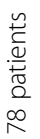

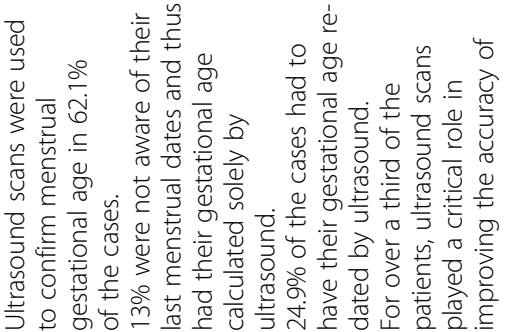

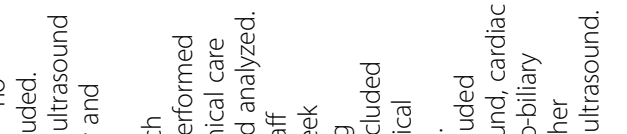

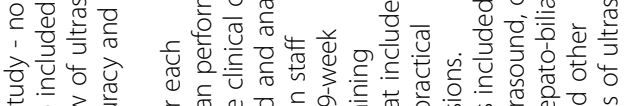

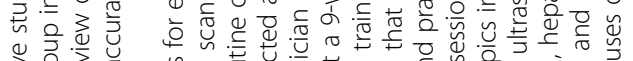

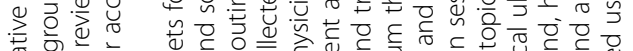

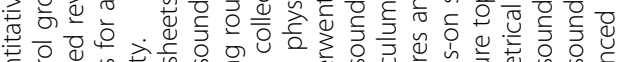

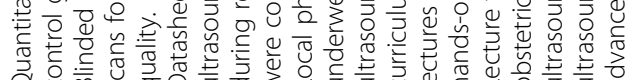

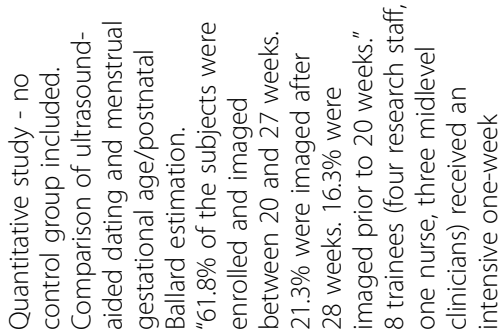

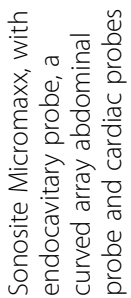

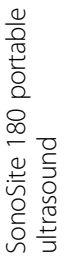

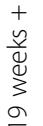

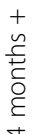

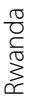

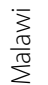

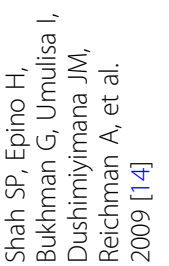




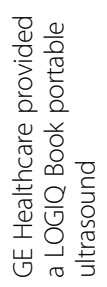

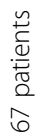

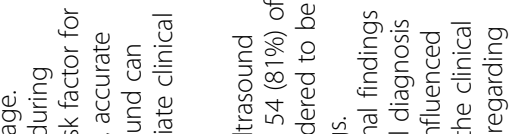

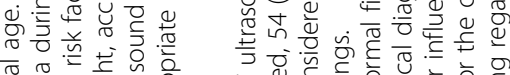

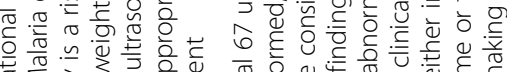

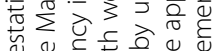

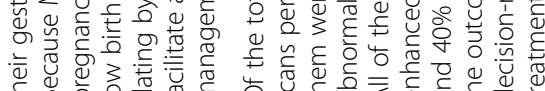

च वं

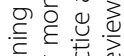

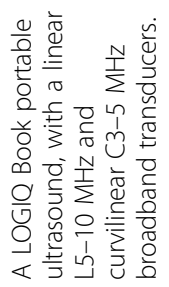

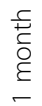

$\underset{\substack{0 \\ \frac{\pi}{0}}}{\frac{\pi}{\pi}}$

$\frac{\sqrt{2}}{\frac{\pi}{\pi}}$

$\frac{\bar{y}}{\frac{0}{0}}$

중

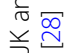

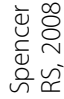

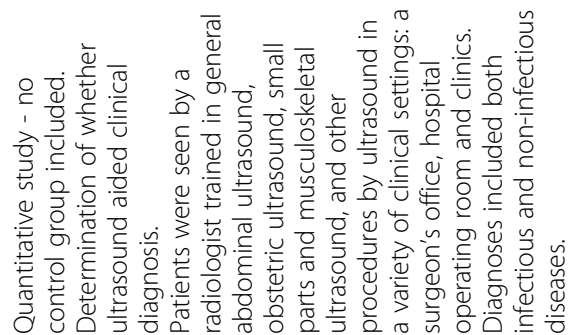

망

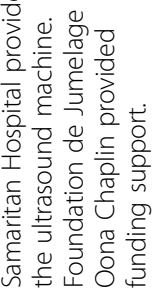

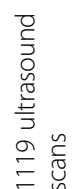

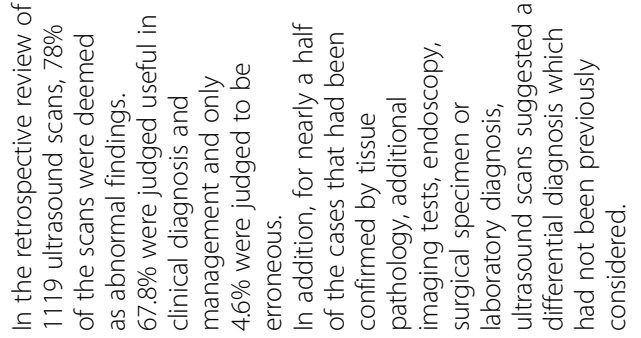

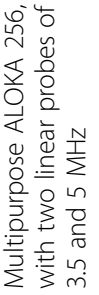

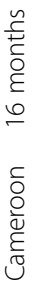

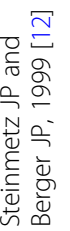




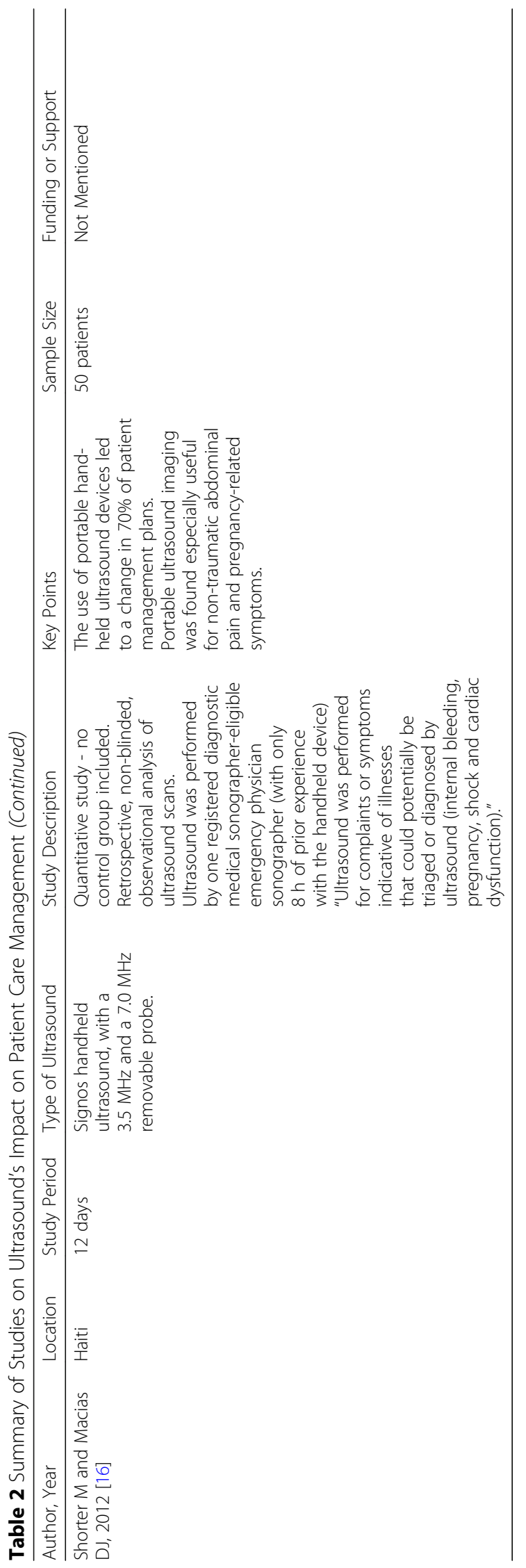




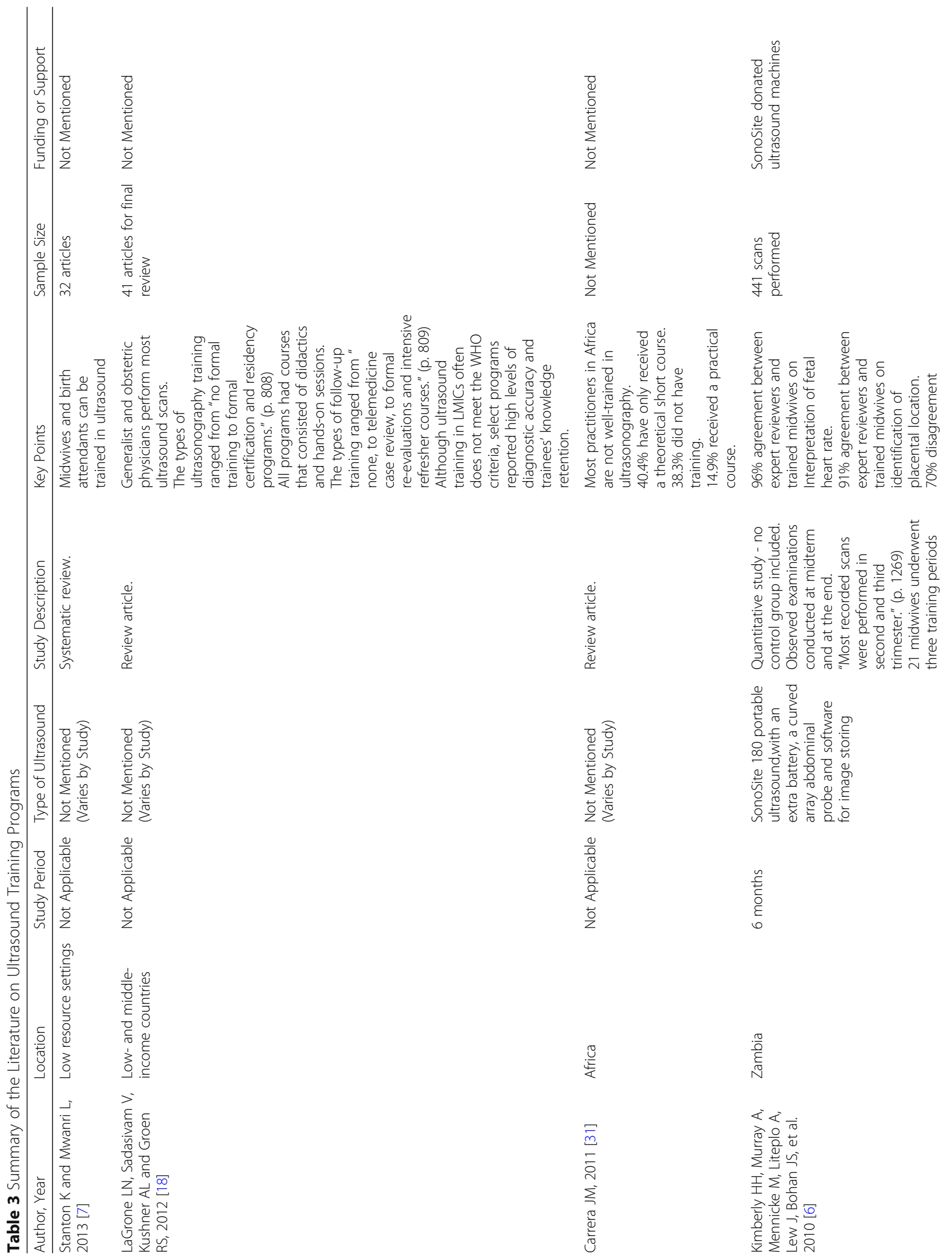



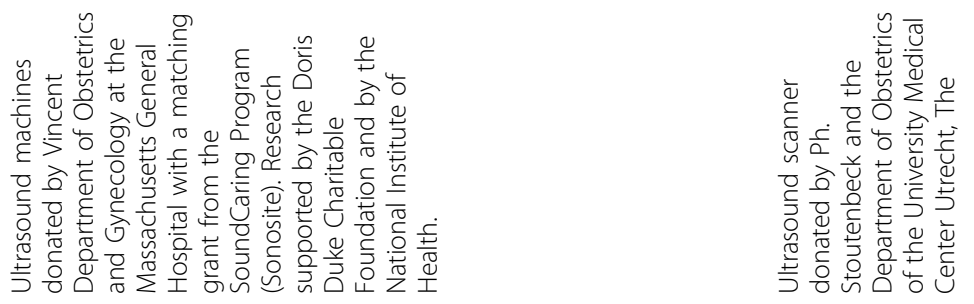

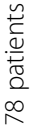

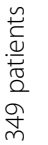

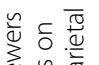

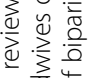

일

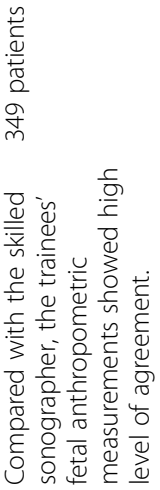

㠃

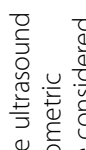

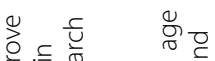

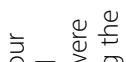

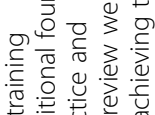

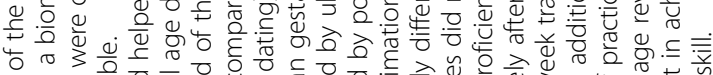

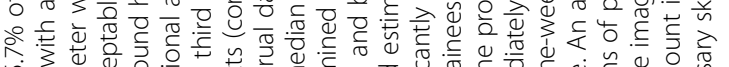

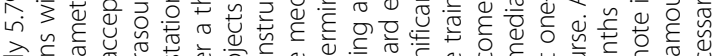

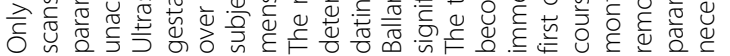

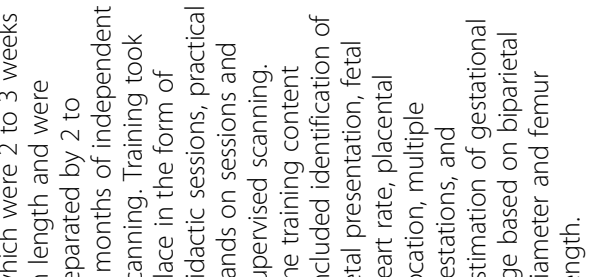
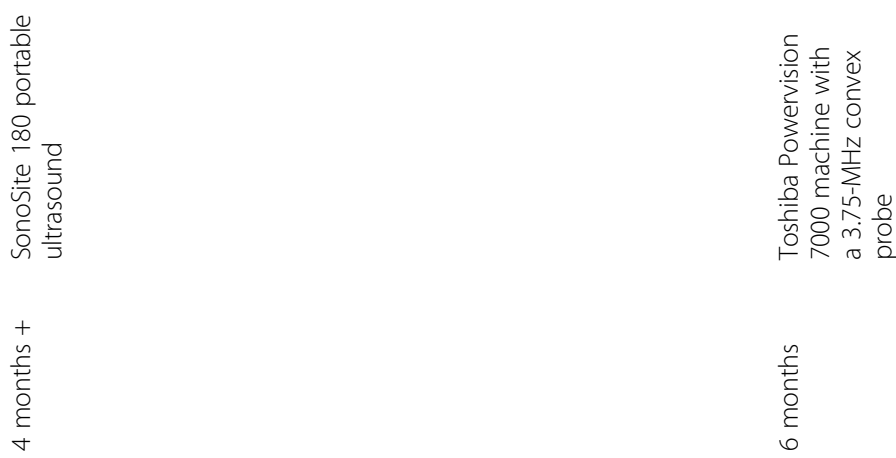

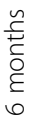

$\frac{\sum}{\sum}$

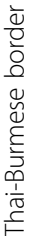

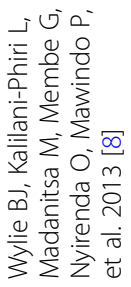

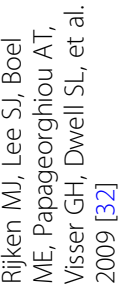




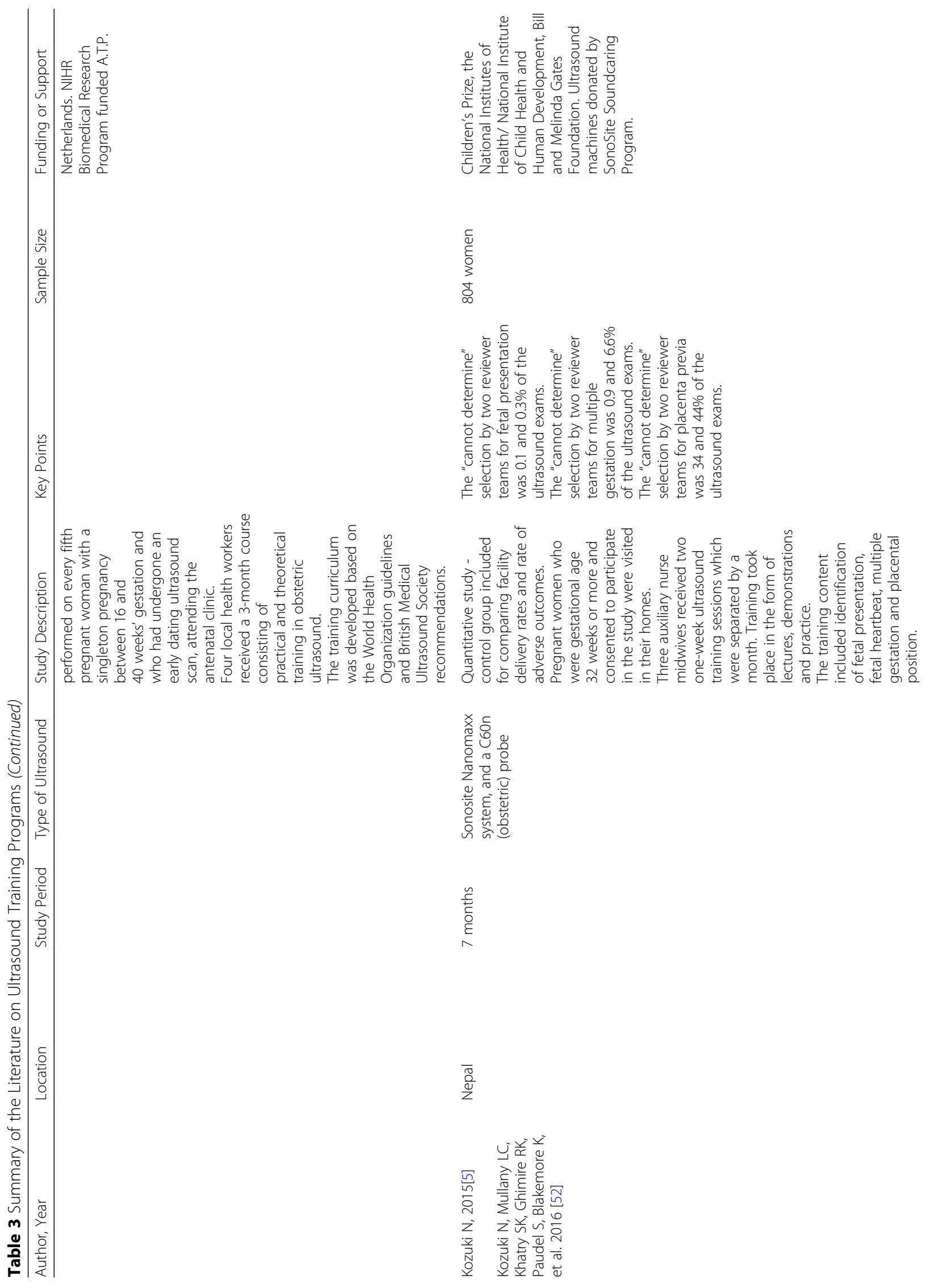




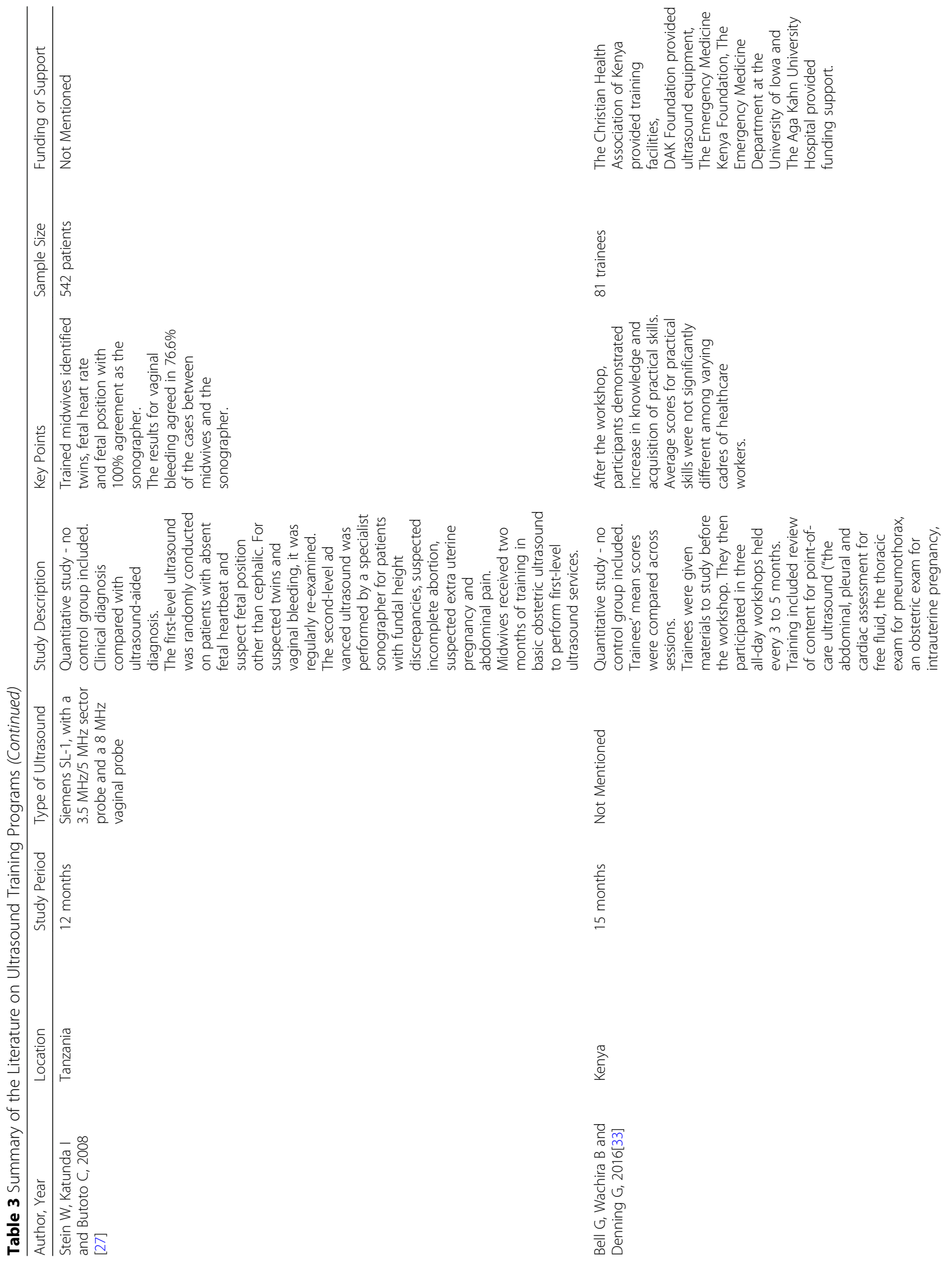



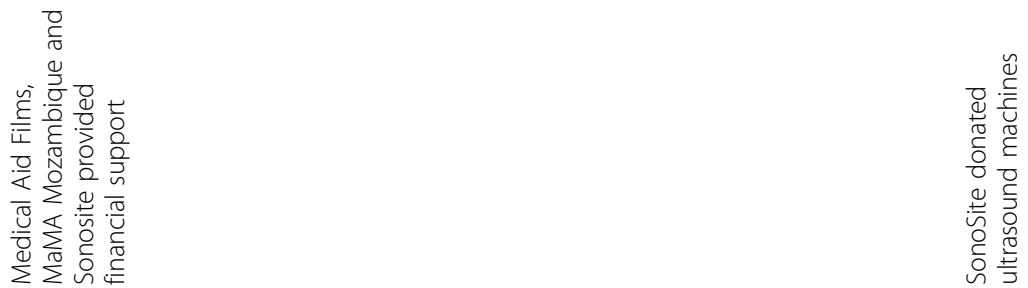

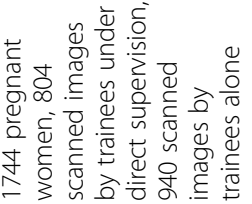

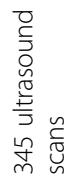
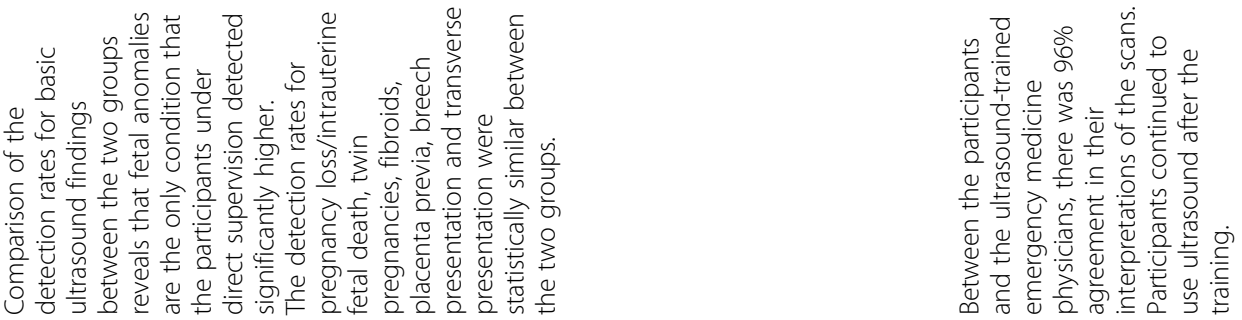

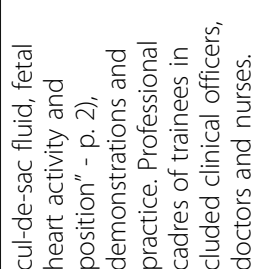

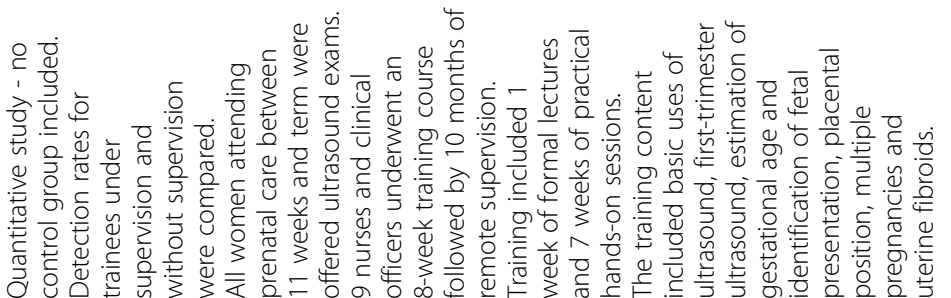

욤

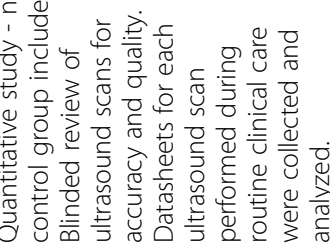

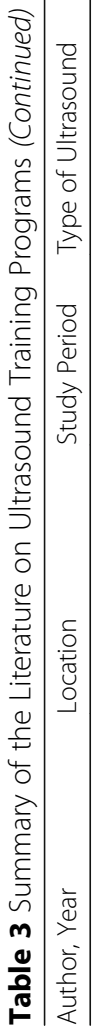

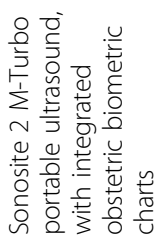

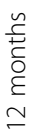

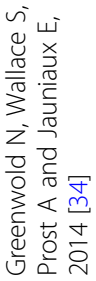

$\frac{\sqrt{10}}{30}$

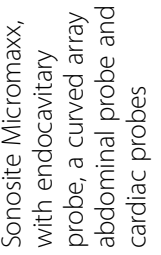

+
$\frac{1}{2}$
$\frac{1}{3}$
a

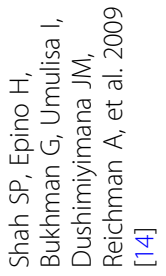




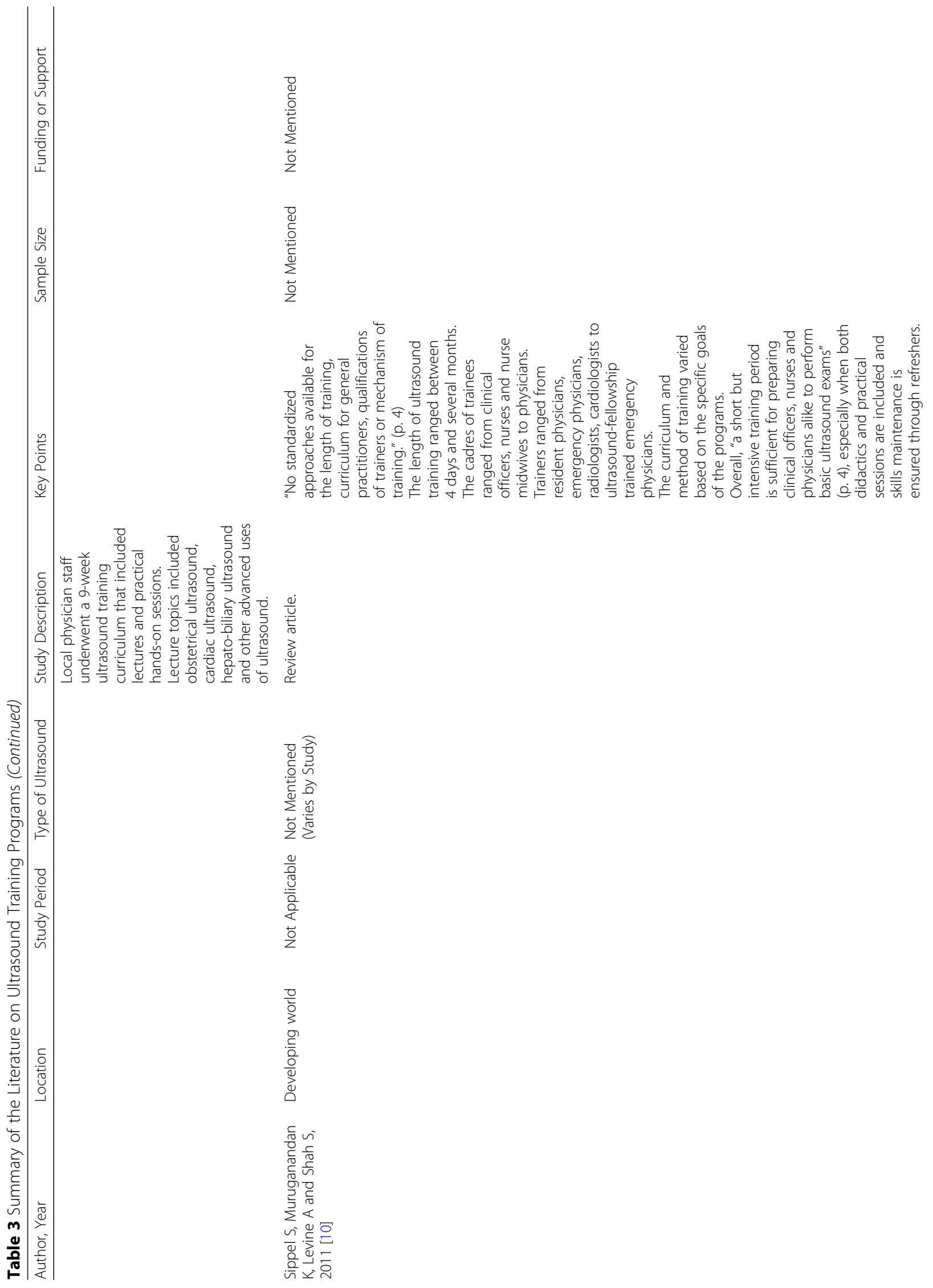




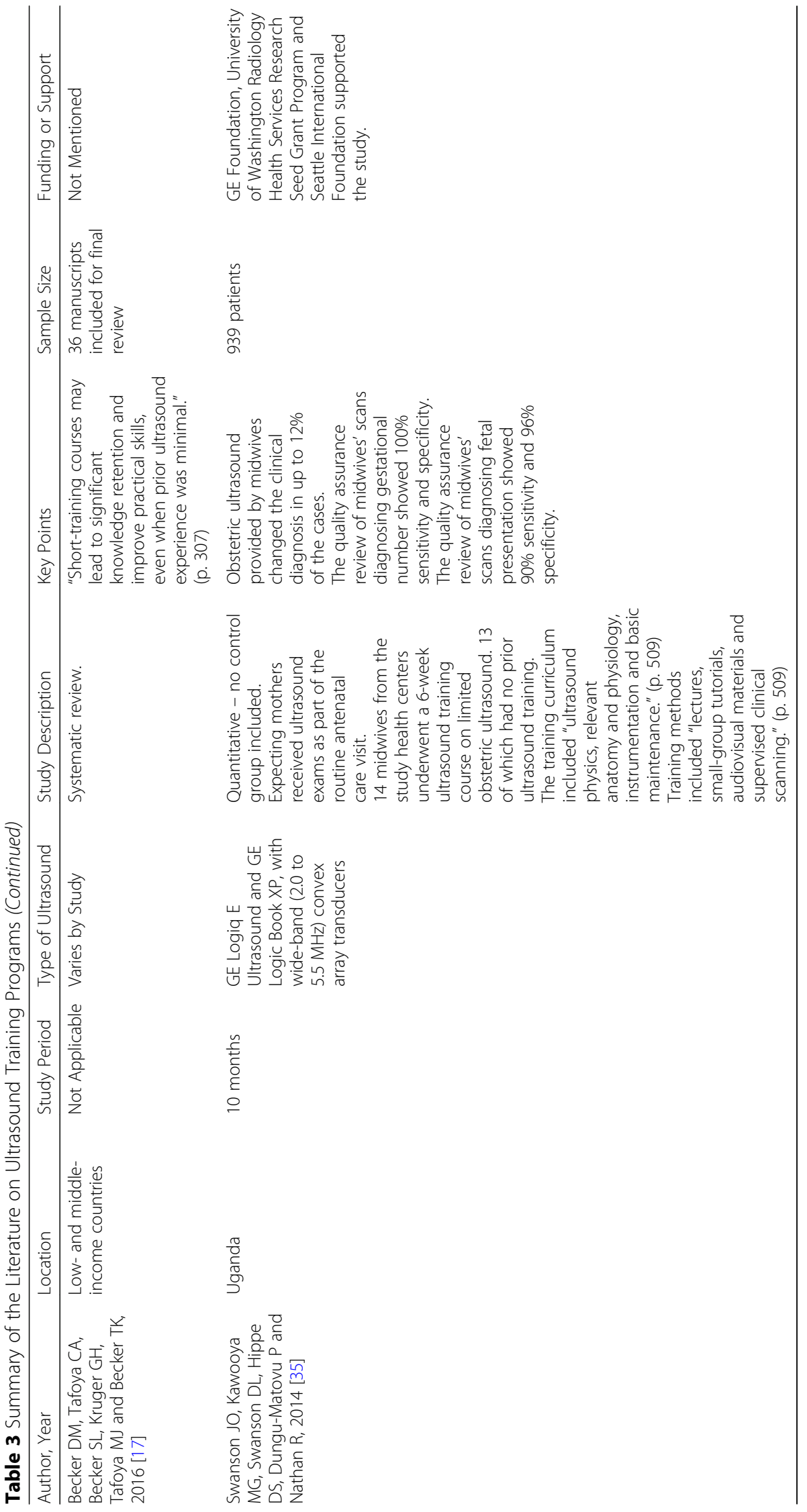


power due to the small sample size [19]. Other studies either did not have enough statistical power to detect significant differences in mortality outcomes [22] or simply speculated that increases in antenatal care visits as a result of ultrasound or postpartum uses of ultrasound will likely reduce mortality outcomes [23, 24].

Some studies that employed a weak study design (limited randomization and absence of control groups) reported that ultrasound services generally appeared to be associated with an increase in the number/proportion of antenatal care use and facility delivery, which is contrary to the findings of a recent large-scale cluster-randomized trial $[20,21]$.

Ross et al. conducted a study at a rural community health center in Uganda with portable ultrasounds [23]. Exams were offered to women during their first antenatal visit and at 32 weeks gestation, and additional scans were performed when they were deemed appropriate [23]. The study noted that ultrasound exam fees were affordable to all patients at about \$2 USD [23]. Lacking a control group, the study utilized a historical control to assess changes in outcome measures pre and post-intervention [23]. Total antenatal care visits at the health center significantly increased from a monthly average of 133.5 visits before the program to 230.3 visits after the program [23]. Over a period of 64 months, the average number of deliveries at the health center also significantly increased from 28.1 deliveries before the program to 45.6 deliveries after the program [23].

Mbuyita et al. conducted a study in Tanzania to determine if mid-level providers were capable of using portable ultrasound machines after training [25]. Compared to baseline data, the number of first antenatal care visits did not change significantly [25]. However, the number of women receiving four or more antenatal care visits increased significantly between baseline $(27.2 \%)$ and endline $(60.3 \%)$ periods in the intervention area [25]. The number of facility deliveries also increased significantly between baseline and endline periods in the intervention area [25].

Lastly, Ross et al. examined the components of routine antenatal care services before and after the introduction of routine ultrasound [26]. The study showed significantly increased rates of anemia treatment, deworming, and two doses of intermittent preventive treatment of malaria (IPT2) after the ultrasound intervention [26].

\section{Patient diagnosis and care management}

Although recent evidence points to ultrasound having no significant effect on mortality, facility delivery and antenatal care use $[20,21]$, there were studies reporting that ultrasound in LMICs helped improve the quality of care for both obstetric and non-obstetric conditions [10]. Muller-Rockstroh, in her narrative description about a hospital in Northwest Tanzania, stated that ultrasound scans helped midwives determine the timing and appropriate mode of delivery. Midwives were able to delay or accelerate timing of delivery and determine appropriate management plans based on ultrasound findings $[24,25]$. The ability of ultrasound to confirm clinically suspected obstetric complications and even improve patient management has been reported in many other studies $[4,6,8,11,12,14,27,28]$.

A study in Malawi reported that despite having a learning curve, mid-level providers were able to confirm or improve determination of gestational age using ultrasound [8]. Correct determination of gestational age is necessary to distinguish premature newborns from newborns who are growth-restricted as the required care and interventions are different [8]. Correct determination of gestational age also has implications for preventing mother-to-child transmission of HIV [7].

The utility of ultrasound has been documented in medical emergencies and disaster settings which include obstetric uses as well. Understandably, portable hand-held or hand-carried ultrasound devices have been employed in these situations where there is unreliable access to power and a high need for rapid triage [17]. During a 12-day disaster relief effort in Haiti after the earthquake in 2010, the use of portable hand-held ultrasound devices led to a change in $70 \%$ of patient management plans [16]. Portable ultrasound imaging was found especially useful for diagnosing non-traumatic abdominal pain and pregnancy-related symptoms [16].

\section{What are key issues related to health personnel? Training of health personnel}

The training of health personnel is a major factor for quality implementation of obstetric ultrasound services, as appropriate patient management relies on the ability of health personnel to use the machine proficiently and interpret findings accurately [7]. In many LMICs, there is a paucity of health personnel who are capable of providing ultrasound services [29].

A WHO Study Group recommended in its 1998 ultrasound manual that candidates for ultrasound training should have at least two to three years of prior healthcare training [30]. Qualified candidates are then recommended to complete at least 6 months of training in a recognized training center including 50 first trimester pregnancy exams and $200 \mathrm{~s}$ and third trimester exams for obstetric applications of ultrasound [30]. It is important to note, however, that recommendations for the different numbers of examinations were given as a guide. A recent review article, which documented training opportunities for ultrasonography in LMICs, concluded that the majority of health personnel using ultrasound in LMICs did not meet the minimum WHO training standards [18]. In Africa, 
$40.4 \%$ of ultrasound service providers completed only a short theoretical course, $14.9 \%$ had practical courses with only $2.1 \%$ occurring in a hospital environment, and $38.3 \%$ had no training at all $[7,31]$. Ultrasonography training largely targeted lower- and mid-level practitioners such as local health workers, nurses and midwives as well as non-radiologist physicians [18]. Although the literature suggests that past trainings were not in compliance with WHO's recommendations, many studies demonstrated that lower- and mid-level providers were capable of providing ultrasound services resulting in improved clinical management $[5,6,8,14,27,29,32-35]$. There is also some evidence that general physicians at rural health facilities can adequately provide ultrasound services in terms of correct use and interpretation of findings [14].

When adequate training materials and methods are used, short intensive training courses have been shown to provide significant acquisition of knowledge and practical skills for all levels of health workers in LMICs [10, 17]. There is also evidence that follow-up refresher trainings can be effective for retention of knowledge and skills $[10,17]$ though the sustainability of these courses after donor funding is expended is not adequately documented. In addition to training, however, it is important to note that there are other issues which are essential in obtaining good clinical readings. These issues include ensuring that the machine is set for the proper application (i.e. obstetric uses) and that the use setting has appropriate lighting, temperature, electrical supply and IT requirements [36]. It is also important to understand the limitations of different ultrasound models and devices. For example, the image quality of portable ultrasound may not be sufficient to identify fetal anomalies and early gestational age.

\section{Concerns about misuse, overuse and miscommunication}

Misuse, overuse and lack of communication between health providers and patients have been frequently cited as concerns in the literature. A study in Uganda demonstrated that over half of all obstetric scans performed were considered inappropriate because they were either scans for gestational age estimation outside of the recommended time period, routine monitoring despite no sign of intrauterine growth restriction or re-assessment of the placental position because of the technical inability to determine it with a previous scan [37]. In another study in Botswana, health providers noted that conventional methods such as history taking and physical examination were neglected because of easy access to ultrasound services [2]. There were indications that even in situations where conventional methods would have sufficed, ultrasound diagnosis was recommended for convenience [2]. Such inappropriate use raises concerns because health providers should not neglect conventional methods of providing care $[2,3]$.
Even when ultrasound services are available, they must be complementary to routine care [4, 7]. This is especially true for obstetric use of ultrasound. For example, estimation of gestational age is more accurate early in pregnancy [8]. As pregnancy progresses, the variation of fetal size increases and it becomes difficult to accurately estimate gestational age by ultrasound alone [8]. Since pregnant women in LMICs often present themselves for antenatal care later in pregnancy, ultrasound dating must be used in conjunction with conventional methods to accurately estimate gestational age [8].

As for cases of misuse, financial incentives for providing unnecessary ultrasound services have been reported as one reason for misuse in LMICs. After the initial ultrasound scan, multiple follow-up scans were often scheduled in private clinics as a way to increase revenue $[38,39]$. Using ultrasound for financial gain or any other reason that is not clinically-based, can significantly reduce the cost-effectiveness of services [1] and drive up the costs paid by women and their families.

Lastly, there is evidence for lack of communication between health providers and patients. A study in Botswana reported that the average time of interaction between providers and patients was $15 \mathrm{~min}$, of which only $15 \%$ were devoted to communicating with the patient [2]. Health providers were preoccupied with the technical aspects of performing an ultrasound scan and patients received very little attention throughout the process [2]. In a study in Iran, none of the study patients reported receiving written information about the purpose of the ultrasound exam, $48 \%$ reported that the ultrasound operator did not answer any questions and $90 \%$ reported that they were never shown the image of the fetus on the ultrasound screen [40]. These findings are of concern as patients' perception of and experience with ultrasound are mainly determined by the quality of their interaction with the health providers [2].

\section{Concerns about fetal sex determination}

Prior studies in different countries document that ultrasound has been illegally used for fetal sex determination. In India, the male-dominant sex ratio for children under 5 years is thought to be associated with fetal sex determination and sex-selective abortions [1]. A population-based study in Delhi, India found that $56 \%$ of respondents either did not know that fetal sex determination was illegal or thought that it was lawful $[9,41]$. In the same study, $2.6 \%$ of respondents had ever requested fetal sex determination and when the female sex of the fetus was disclosed, over $63 \%$ of them were aborted $[9,41]$. In a study in Nepal, $6.8 \%$ of surveyed pregnant women received ultrasound exams for fetal sex determination despite it being unlawful [42]. The study also found that compared to women who had at least one live born son prior to the recent 
pregnancy, women with no live born sons and three or more live born daughters had 1.55 higher odds of receiving an ultrasound exam, which may suggest use for fetal sex determination [42]. Other popular reasons for determining fetal sex were reported to be curiosity and preparation for the baby $[43,44]$.

Negative consequences of fetal sex determination go beyond obvious legal and ethical violations. Incorrect assessment of the fetal sex can also result in negative experiences for women, especially in settings where son preference is high. Incorrect assessment of the fetal sex is not uncommon. In a study in Ghana, fetal sex was accurately determined in only $86.5 \%$ of the cases [45]. A study in Nigeria reported that incorrect assessment of the fetal sex, particularly for mistaking female fetuses as males, resulted in marital conflict, physical violence from husbands, regret of undergoing tubal ligation, negative perception towards ultrasound and negative feelings towards the newborns [46]. Such negative consequences can be exacerbated when accreditation and regulation for ultrasound use are limited $[9,47]$. Ethical training for health providers on appropriate uses of ultrasound and regulations for both public and private clinics are important [7].

\section{What issues are important to patients? \\ Patient perception on ultrasound services}

In the studies reviewed, women in LMICs generally held positive views about ultrasound services [23]. Rijken et al. found that on the Thai-Burmese border, ultrasound was considered a tool that could increase safety during pregnancy and childbirth $[23,48]$. In a rural Botswana district hospital, pregnant women showed signs of trusting the ultrasound results more than their own bodily sensations to confirm a live fetus [2]. The women expressed relief that "there was life in the baby" (p. 697) [2]. These women also referred to the ultrasound experts as the "Whites" (p. 697) and regarded the same ultrasound services provided by African health providers as substandard [2].

Cultural resistance to ultrasound services was not reported to be a major problem. A study in Zambia reported that patients would often wait in line for ultrasound exams, even after clinic hours were over [6]. In addition, many patients who came for antenatal visits stated that availability of ultrasound was their motivation for attendance [6]. A qualitative study in Tanzania reported that the majority of women desired to receive ultrasound exams despite the lack of understanding about the benefits and the procedures [49]. Those who did not view ultrasound favorably thought that ultrasound would cause harm to the fetus [49].

Negative perceptions or misconceptions about ultrasound were reported in other studies as well [40, 50]. Women interviewed in a study in rural Kenya perceived that undergoing an ultrasound exam meant there was an emergency or a problem with the pregnancy [50]. However, all interviewed women perceived ultrasound to add significant value in reassuring the health and progress of the baby [50]. In another study in Iran, 39\% of women chose not to undergo an ultrasound exam due to the following reasons: ultrasound can be harmful (especially with regards to fetal malformation); results are not important; exams are expensive; and busy schedules [40].

Motivation for seeking ultrasound services as well as access to ultrasound services have been documented to differ by social class. A study in Nepal found that the adjusted odds of receiving an ultrasound exam were 3.4 times higher for women who had 7 to 10 years of education and 10.28 times higher for women who had more than 10 years of education compared to women with no formal education [42]. In sub-Saharan Africa, access to obstetric ultrasound in rural areas has shown to be as low as $6 \%[7,31]$.

Providers' explanations or lack of explanations about the ultrasound scan play a role in terms of patient perception and satisfaction. Women who received ultrasound services in a rural setting in Botswana described that turning the light off before the examination was an unusual experience [2]. Patients normally expect examination rooms to be "brightly lit" (p. 694) [2]. In a study in southeast Nigeria, $70 \%$ of study participants reported that they did not interact with the sonographers, $24 \%$ reported being afraid prior to the scan, $11 \%$ reported being afraid during the scan and $4 \%$ reported being afraid after the scan [51].

\section{What are potential issues with the ultrasound device? Maintenance}

Although there are no previous studies rigorously testing the durability of ultrasound machines in LMICs, some studies provide anecdotal accounts. Kozuki et al. describes having to replace refurbished portable ultrasound machines four times in the span of 17 weeks in a study in Nepal due to hardware and software errors [5,52]. In another study by Kimberly et al., portable ultrasound machines performed well even in excess heat, humidity, dust and long travels in a 6-month study [6]. At the 1-year follow-up visit, however, $38 \%$ of the midwives who responded to a follow-up survey cited problems with the ultrasound machine [6]. These problems included depletion of ultrasound gel and flickering image on the ultrasound screen [6]. Another study reported that maintenance was not an issue during the 5-month study period [14]. In fact, a study conducted in extreme conditions of the Amazon jungle reported that portable ultrasound machines functioned well for two two-week trips [53]. However, there is limited evidence for maintenance beyond the research study period. One study 
describes that establishing a maintenance protocol within routine health systems can be long and difficult [24]. In this study, such difficulty left many ultrasound machines unrepaired [24].

\section{Cost}

In high-income countries, there has been many studies assessing the cost effectiveness of using ultrasound to identify fetal abnormalities, as demonstrated by a 2002 review [54]. Cost effectiveness studies are less common for LMICs. Only a few studies provided an overview of program costs and the realized benefits. Bussmann and colleagues reported that in a district hospital in Botswana, initial capital and recurrent costs of the ultrasound were considered affordable, relative to the overall unspent hospital budget in the study period [4]. They also found that "the marginal cost of providing an ultrasound was less than a quarter of providing an X-ray examination" (p. 1030) [4]. The average and marginal costs of an ultrasound diagnosis in improving patient management appeared to be affordable as well, 56.58 USD and 0.64 USD respectively [4]. Lastly, the average and marginal costs of potentially improving a health outcome through an actual change in therapy, were considered affordable, 260.79 USD and 2.93 USD respectively [4]. Overall, the study concluded that providing ultrasound scans in Botswana was financially feasible [4]. Another study in Nepal estimated the impact of ultrasound on the potential to avert perinatal deaths attributable to non-cephalic birth, multiple birth and placenta previa $[5,52]$. The study estimated that with an early ultrasound diagnosis, a total of 160 potential perinatal deaths could be averted, which translates to about 65 USD saved per life [5, 52]. This estimation was derived based on the assumption that all early diagnoses will lead to the prevention of perinatal deaths [5, 52], likely overestimating the true impact. However, it also did not adjust for potential disability life years averted by preventing maternal mortality or morbidity $[5,52]$. Hence, the estimated impact on averting potential perinatal deaths does not capture the full range of benefits that early ultrasound diagnosis offers.

In summary, there is a lack of high quality cost effectiveness studies on obstetric ultrasound in the literature [54]. The majority of published studies are from high-income countries, and they did not include discussions about longer term costs or cost incurred to women [54].

\section{Discussion}

This review examined various factors associated with introducing obstetric ultrasound in LMICs. A recent cluster-randomized trial found that use of ultrasound in rural health centers did not impact antenatal care attendance, facility delivery, maternal mortality, neonatal mortality and stillbirths [20]. A related case study further suggested that scale-up of routine antenatal ultrasound is not warranted [55]. Other studies with less rigorous designs, however, found that ultrasound use was associated with the increase of antenatal care attendance [23, 25] and facility delivery $[6,7,23,25,49]$. Although antenatal ultrasound use did not affect mortality measures, there is evidence suggesting that ultrasound can confirm and improve patient management for both obstetric and non-obstetric conditions $[4,6,8,10-12,14,27,28]$. One potential concern with the introduction of ultrasound is whether it will disrupt existing services routinely provided at the health facility. Muller-Rockstroh describes that select district hospitals in Tanzania decided to train nurse-midwives for ultrasound use instead of training radiographers or radiography assistants [24]. This is because use of ultrasound by radiographers would have disrupted the X-ray services also provided by them [24]. Even when disruption of other services is not an issue, there is still a disagreement in the literature about routine versus selective provision of ultrasound services. Kongnyuy and van den Broek argue that ultrasonography should be routinely performed for all women because it is regarded as safe and affordable [1]. It could also save costs by detecting abnormalities early in pregnancy $[1,9]$. Papp and Fekete support routine ultrasound screening on the basis that 85 to $90 \%$ of congenital malformations occur without maternal or family antecedents and therefore, selective ultrasound screening may miss a lot of cases that cannot be deducted based on previous medical history [56]. Tautz and colleagues offer a counter-argument, however, that there is insufficient evidence for ultrasound to be recommended as a routine screening tool [2]. Instead, they argue that selective use of ultrasound during the antenatal period can complement diagnoses that remain uncertain after other clinical tests have been performed [2]. Hofmeyr also adds that routine ultrasound services for patients with already confirmed pathologies may risk wasting human resources that could be allocated more efficiently elsewhere $[9,57]$.

While there is a lack of consensus in the literature, the WHO issued a brief which recommends that pregnant women receive only one ultrasound scan before 24 weeks gestation for accurate determination of gestational age, early identification of fetal anomalies and multiple pregnancies, appropriate preparation and management of preterm and post-term births and helping create a positive pregnancy experience [58]. For those who did not receive a scan during this period, a later scan may be considered to determine fetal number, presentation and placental location [58]. However, ultrasound may be used more than once depending on the specific patient condition.

Additional guidelines and considerations are discussed in the literature for large-scale implementation of ultrasound. 


\section{Health personnel training}

Mid- and lower-level health providers demonstrated competence in using ultrasound and in making accurate diagnosis with only a short intensive training $[5,6,8,10,14,17$, 27, 29, 32-34]. Although past training programs were largely successful, a few points have been consistently highlighted in the literature for improving future endeavors.

First, because past training programs varied greatly in duration and content, there is a need for an internationally recognized standard of training or a certificate program $[59,60]$. In addition, an ideal training module would minimize the interruption to local health workers' schedules and allow for practical hands-on sessions and applications [59, 61].

Second, training programs should incorporate management lessons such as short-term and long-term maintenance of the ultrasound machine, image storage, image review and quality assurance as a part of the curriculum $[18,59]$. Attention to these management topics will increase the likelihood that ultrasound machines are continuously being used after the training has concluded, particularly in rural and isolated locations $[18,59]$.

Third, training programs should ensure that continuing education is available for participants after the short intensive training courses conclude [59]. This may be in the form of follow-up refresher sessions, direct supervision, review of donated textbooks, review of publicly accessible or affordable journals, presentations and teleconferencing [3]. Remote learning and supervision via teleconferencing could potentially reduce costs and have a positive impact on the quality of care [62]. Providers in LMICs have also shown receptiveness to the possibility of distance learning modules $[7,60]$. This option is especially appealing for rural health workers because commitment to lengthy training programs and continuous in-person follow up sessions may be unrealistic [61].

Fourth, training programs should sensitize health providers in legal and ethical conduct regarding ultrasound use and towards patients' desire for being informed about their care [2]. This is because overuse and misuse $[2,37-39]$, determining fetal sex $[1,5,9,41]$ and the lack of communication between health providers and patients were found to be major concerns regarding ultrasound use in LMICs [2].

In the long term, a more sustainable solution would be to involve local radiology societies and training institutions to increase support for locally trained specialized sonographers $[7,63]$. This trend is already underway as a number of training institutions and associations have been established in Africa in recent years [7].

\section{Ultrasound acquisition and maintenance}

Several factors must be considered when acquiring ultrasound machines and setting up maintenance protocols
[59, 64]. First, various features of the ultrasound machine - image quality, level of radiation and safety, easy and robust operability, transducers, ultrasound gel, supplies for cleaning, maintenance service and storage must be thoroughly considered [59, 64]. Second, and of key importance is the selection of an ultrasound machine that serves the purpose for which it is intended (e.g. the quality of the image resolution determines what can be diagnosed with a particular machine). Third, there must be a comprehensive assessment of the practice environment in which ultrasound will be used [64]. The reliability of electricity supply, the volume of patients received at the health facility, and the intended use/types of diagnoses expected may determine the local preference for full-size versus portable ultrasound machines [59]. For example, a high volume hospital with a more reliable source of electricity might prefer a full-size, plug-in ultrasound because of the larger size rendering protection against theft. For smaller health clinics operating in rural areas, using a battery-operated portable ultrasound machine may be more practical. Even with portable ultrasound machines, security measures can be taken to guard against theft or damage. These measures include storing the machines in a locked room or placing it under constant observation when there is a high demand for use $[55,59]$. For health facilities that already own full-size ultrasound machines, however, purchasing portable ultrasound machines might be redundant [3]. Third, durability of ultrasound machines as well as the manufacturer's local capacity for maintenance should be considered. It may also be important to train in-house mechanics to take primary responsibility over minor repairs [59].

\section{Cost-effectiveness}

Recent studies that included descriptions about their program's costs and the realized benefits concluded that providing ultrasound services was financially feasible and cost-effective $[4,5]$. Yet, there is still a lack of high quality cost-effectiveness studies conducted in LMICs [54]. This calls for more studies to be conducted with rigorous designs [54], so that a true comparison of the added value of the service and the intervention costs versus the counterfactual can be made. It is also essential to define the package of services in which effectiveness is evaluated. Key questions to consider are how recommended antenatal ultrasound services [58] would be integrated into existing maternity services most effectively and what potential trade-offs exist with other essential services in resource-constrained settings. A recent case study from the Democratic Republic of the Congo reported that the success of implementing structural changes in the health system would rely on the level of stakeholder effort, motivation, political will and financial 
and human resources available [55]. In the absence of these elements, streamlined integration into the health system would be challenging.

\section{Promoting cultural competence}

Although there was a tendency of overestimating the diagnostic capabilities of ultrasound [2,7], patients generally seemed to hold positive views about ultrasound services [23]. Cultural resistance to ultrasound was also not a major issue $[6,49]$. In certain cultures, however, viewing the insides of a pregnant mother or projecting the image of a fetus might be considered offensive [3]. Introduction of ultrasound services in these settings may require investment into community engagement about the benefits of ultrasound during pregnancy [3]. As one strategy, education efforts could highlight areas where conventional methods are similar to the procedures of ultrasound, so that any uneasiness related to trying new technology may be mitigated. In Tanzania, for example, the resemblance between applying ultrasound gel and rubbing local medicine on the women's belly for diagnosing problematic pregnancies seemed to help establish women's trust [24]. Including husbands in the intervention may also be a culturally appropriate strategy in some cases as one study found that they played a role in encouraging women to seek antenatal ultrasound exams [23].

\section{Conclusion}

This literature review focused on obstetric uses of ultrasound in LMICs. As cost of obstetric ultrasound becomes more affordable in LMICs, it is essential to assess the benefits, trade-offs and potential drawbacks of large-scale implementation. Additionally, there is a need to more clearly identify the capabilities and the limitations of ultrasound, particularly within the context of limited training of providers, to ensure that the purpose for which an ultrasound is intended is actually feasible (e.g. the image quality of portable ultrasound is not sufficient to identify fetal anomalies and early gestational age). We found evidence of obstetric uses of ultrasound improving patient management. However, there was evidence that ultrasound use is not associated with reducing maternal, perinatal or neonatal mortality. Patients in various studies reported to have both positive and negative perceptions and experiences related to ultrasound and lastly, illegal use of ultrasound for determining fetal sex was raised as a concern.

\section{Funding}

This study was carried out with support provided by the United States Agency for International Development (USAID) through MEASURE Evaluation (cooperative agreement AID-OAA-L-14-00004). We are grateful to the Carolina Population Center and its NIH Center grant (P2C HD050924) and its training grant (T32 HD007168) for general support.
The views and opinions expressed in this paper are those of the authors and not necessarily the views and opinions of the United States Agency for International Development.

\begin{abstract}
Authors' contributions
Study concept and design: ETK, KS, AM, DA. Acquisition of studies to review: ETK, KS, AM, DA, NK. Analysis and interpretation of the studies: ETK, KS, AM, DA. Drafting of the manuscript: ETK. Critical revision of the manuscript for important intellectual content: ETK, KS, AM, DA, NK. All authors read and approved the final manuscript.
\end{abstract}

Ethics approval and consent to participate

Not applicable.

\section{Consent for publication}

Not applicable.

\section{Competing interests}

The authors declare that they have no competing interests.

\section{Publisher's Note}

Springer Nature remains neutral with regard to jurisdictional claims in published maps and institutional affiliations.

\section{Author details}

${ }^{1}$ Department of Maternal and Child Health, Gillings School of Global Public Health, University of North Carolina at Chapel Hill, 135 Dauer Dr, Chapel Hill, NC 27516, USA. ${ }^{2}$ Carolina Population Center, University of North Carolina at Chapel Hill, Carolina Square, Suite 210, 123 West Franklin St, Chapel Hill, NC 27516, USA. ${ }^{3}$ MEASURE Evaluation, Carolina Population Center, University of North Carolina at Chapel Hill, Carolina Square, Suite 330, 123 West Franklin St, Chapel Hill, NC 27516, USA. ${ }^{4}$ US Agency for International Development, 1300 Pennsylvania Avenue, NW, Washington, DC 20523, USA. ${ }^{5}$ International Rescue Committee, 1730 M St. NW Suite 505, Washington, DC 20036, USA. ${ }^{6}$ Department of International Health, Johns Hopkins Bloomberg School of Public Health, 615 N. Wolfe St., Baltimore, MD 21205, USA.

Received: 16 April 2018 Accepted: 13 July 2018

Published online: 20 July 2018

\section{References}

1. Kongnyuy EJ, van den Broek N. The use of ultrasonography in obstetrics in developing countries. Trop Dr. 2007;37:70-2.

2. Tautz S, Jahn A, Molokomme I, Görgen R. Between fear and relief: how rural pregnant women experience foetal ultrasound in a Botswana district hospital. Soc Sci Med. 2000:50:689-701.

3. Harris RD, Marks WM. Compact ultrasound for improving maternal and perinatal Care in low-Resource Settings: review of the potential benefits, implementation challenges, and public health issues. J Ultrasound Med. 2009:28:1067-76.

4. Bussmann H, Koen E, Arhin-Tenkorang D, Munyadzwe G, Troeger J. Feasibility of an ultrasound service on district health care level in Botswana. Tropical Med Int Health. 2001;6:1023-31.

5. Kozuki N. Epidemiology, Diagnosis, and Care-seeking related to Risk Factors for Intrapartum-related Fetal and Neonatal Death in Rural Nepal [Doctoral dissertation]; 2015

6. Kimberly HH, Murray A, Mennicke M, Liteplo A, Lew J, et al. Focused maternal ultrasound by midwives in rural Zambia. Ultrasound Med Biol. 2010;36:1267-72. https://doi.org/10.1016/j.ultrasmedbio.2010.05.017.

7. Stanton K, Mwanri L. Global maternal and child health outcomes: the role of obstetric ultrasound in low resource settings. World journal of preventive medicine; 2013. Available: http://pubs.sciepub.com/jpm/1/3/3/.

8. Wylie BJ, Kalilani-Phiri L, Madanitsa M, Membe G, Nyirenda O, et al. Gestational age assessment in malaria pregnancy cohorts: a prospective ultrasound demonstration project in Malawi. Malar J. 2013;12:183. https:// doi.org/10.1186/1475-2875-12-183.

9. Groen RS, Leow JJ, Sadasivam V, Kushner AL. Review: indications for ultrasound use in low- and middle-income countries. Tropical Med Int Health. 2011;16:1525-35. https://doi.org/10.1111/j.1365-3156.2011.02868.x. 
10. Sippel S, Muruganandan K, Levine A, Shah S. Review article: use of ultrasound in the developing world. Int J Emerg Med. 2011;4:72. https://doi. org/10.1186/1865-1380-4-72.

11. Kotlyar S, Moore CL. Assessing the utility of ultrasound in Liberia. J Emerg Trauma Shock. 2008;1:10-4.

12. Steinmetz JP, Berger JP. Ultrasonography as an aid to diagnosis and treatment in a rural African hospital: a prospective study of 1,119 cases. Am J Trop Med Hyg. 1999;60:119-23.

13. Ahmad S, Kampondeni S, Molyneux E. An experience of emergency ultrasonography in children in a sub-Saharan setting. Emerg Med J. 2006;23: 335-40. https://doi.org/10.1136/emj.2005.028761.

14. Shah SP, Epino H, Bukhman G, Umulisa I, Dushimiyimana JM, et al. Impact of the introduction of ultrasound services in a limited resource setting: rural Rwanda 2008. BMC Int Health Hum Rights. 2009;9:4. https://doi.org/10.1186/ 1472-698X-9-4.

15. Doehring-Schwerdtfeger E, Abdel-Rahim IM, Dittrich M, Mohamed-Ali Q, Franke D, et al. Ultrasonography as a diagnostic aid for a district hospital in the tropics. Am J Trop Med Hyg. 1992;46:727-31.

16. Shorter M, Macias DJ. Portable handheld ultrasound in austere environments: use in the Haiti disaster. Prehosp Disaster Med. 2012;27:1727. https://doi.org/10.1017/S1049023X12000611

17. Becker DM, Tafoya CA, Becker SL, Kruger GH, Tafoya MJ, et al. The use of portable ultrasound devices in low- and middle-income countries: a systematic review of the literature. Tropical Med Int Health. 2016;21:294311. https://doi.org/10.1111/tmi.12657.

18. LaGrone LN, Sadasivam V, Kushner AL, Groen RS. A review of training opportunities for ultrasonography in low and middle income countries. Tropical Med Int Health. 2012;17:808-19. https://doi.org/10.1111/j.1365-3156. 2012.03014.x.

19. Van Dyk B, Motto JA, Buchmann EJ. Routine second-trimester ultrasound for low risk pregnancies in a south African community. Int J Gynaecol Obstet. 2007;98:257-8. https://doi.org/10.1016/j.ijgo.2007.03.034.

20. Mcclure E, Goldenberg R, Swanson D, Saleem S, Esamai F, et al. 3. Routine antenatal ultrasound in low/middle income countries: a cluster randomized trial. Am J Obstet Gynecol Oral Plenary Session I. 2017. Available: https:// www.ajog.org/article/S0002-9378(16)30983-8/pdf.

21. McClure EM, Nathan RO, Saleem S, Esamai F, Garces A, et al. First look: a cluster-randomized trial of ultrasound to improve pregnancy outcomes in low income country settings. BMC Pregnancy Childbirth. 2014;14:73. https:// doi.org/10.1186/1471-2393-14-73.

22. Geerts LT, Brand EJ, Theron GB. Routine obstetric ultrasound examinations in South Africa: cost and effect on perinatal outcome--a prospective randomised controlled trial. Br J Obstet Gynaecol. 1996;103:501-7.

23. Ross AB, DeStigter KK, Rielly M, Souza S, Morey GE, et al. A low-cost ultrasound program leads to increased antenatal clinic visits and attended deliveries at a health care clinic in rural Uganda. PLoS One. 2013:8:e78450. https://doi.org/10.1371/journal.pone.0078450.

24. Müller-Rockstroh B. Appropriate and appropriated technology: lessons learned from ultrasound in Tanzania. Med Anthropol. 2012;31:196-212. https://doi.org/10.1080/01459740.2011.639105.

25. Mbuyita S, Tillya R, Godfrey R, Kinyonge I, Shaban J, et al. Effects of introducing routinely ultrasound scanning during ante Natal Care (ANC) clinics on number of visits of ANC and facility delivery: a cohort study. Arch Public Health. 2015;73:36. https://doi.org/10.1186/s13690-015-0086-8.

26. Ross AB, DeStigter KK, Coutinho A, Souza S, Mwatha A, et al. Ancillary benefits of antenatal ultrasound: an association between the introduction of a low-cost ultrasound program and an increase in the numbers of women receiving recommended antenatal treatments. BMC Pregnancy Childbirth. 2014;14:424. https://doi.org/10.1186/s12884-014-0424-9.

27. Stein W, Katunda I, Butoto C. A two-level ultrasonographic service in a maternity care unit of a rural district hospital in Tanzania. Trop Dr. 2008;38: 125-6. https://doi.org/10.1258/td.2007.070045.

28. Spencer JK, Adler RS. Utility of portable ultrasound in a community in Ghana. J Ultrasound Med. 2008:27:1735-43.

29. Robert Tillya SM. Uptake of training on Vscan by midlevel providers working in rural health facilities in Tanzania: implications for reliability. Journal of Biosafety \& Health Education. 2014;02 https://doi.org/10.4172/2332-0893.1000123.

30. WHO Study Group on Training in Diagnostic Ultrasound: Essentials, Principles and Standards (1996: Philadelphia, Pennsylvania), Organization WH (1998) Training in diagnostic ultrasound : essentials, principles and standards : report of a WHO study group. Available: http://apps.who.int/iris/handle/10665/42093.
31. Carrera JM. Obstetric ultrasounds in Africa: is it necessary to promote their appropriate use? Donald School Journal of Ultrasound in Obstetrics \& Gynecology. 2011;5:289-96. https://doi.org/10.5005/jp-journals-10009-1205.

32. Rijken MJ, Lee SJ, Boel ME, Papageorghiou AT, Visser GH, et al. Obstetric ultrasound scanning by local health workers in a refugee camp on the ThaiBurmese border. Ultrasound Obstet Gynecol. 2009;34:395-403. https://doi. org/10.1002/uog.7350

33. Bell G, Wachira B, Denning G. A pilot training program for point-of-care ultrasound in Kenya. African Journal of Emergency Medicine. 2016;6:132-7. https://doi.org/10.1016/j.afjem.2016.03.002.

34. Greenwold N, Wallace S, Prost A, Jauniaux E. Implementing an obstetric ultrasound training program in rural Africa. Int J Gynaecol Obstet. 2014;124: 274-7. https://doi.org/10.1016/j.ijgo.2013.09.018.

35. Swanson JO, Kawooya MG, Swanson DL, Hippe DS, Dungu-Matovu P, et al. The diagnostic impact of limited, screening obstetric ultrasound when performed by midwives in rural Uganda. J Perinatol. 2014;34:508-12. https:// doi.org/10.1038/jp.2014.54.

36. The Society and College of Radiographers. Standards for the provision of an ultrasound service; 2015

37. Mubuuke AG, Kiguli-Malwadde E, Businge F, Byanyima RK. Utilisation of obstetric sonography at a peri-urban health Centre in Uganda. Pan Afr Med J. 2010;7:24.

38. Bashour H, Hafez R, Abdulsalam A. Syrian women's perceptions and experiences of ultrasound screening in pregnancy: implications for antenatal policy. Reprod Health Matters. 2005;13:147-54.

39. Gammeltoft T, Nguyen HT. The commodification of obstetric ultrasound scanning in Hanoi, Viet Nam. Reprod Health Matters. 2007;15:163-71. https://doi.org/10.1016/S0968-8080(06)29280-2.

40. Ranji A, Dykes AK. Ultrasound screening during pregnancy in Iran: womens' expectations, experiences and number of scans. Midwifery. 2012;28:24-9. https://doi.org/10.1016/j.midw.2010.10.005.

41. Chaturvedi S, Chhabra P, Bharadwaj S, Smanla S, Kannan AT, et al. Fetal sexdetermination in Delhi: a population-based investigation. Trop Dr. 2007:37:98-100.

42. Kozuki N, Katz J, Khatry SK, Tielsch JM, LeClerq SC, et al. Community survey on awareness and use of obstetric ultrasonography in rural Sarlahi District, Nepal. Int J Gynaecol Obstet. 2016;134:126-30. https://doi.org/10.1016/j.jjo. 2016.01.015.

43. Okeke TC, Enwereji JO, Okoro OS, Iferikigwe ES, Ikeako LC, et al. Desire for prenatal gender disclosure among primigravidae in Enugu, Nigeria. Patient Prefer Adherence. 2015;9:429-33. https://doi.org/10.2147/PPA.S77029.

44. Shukar-Ud-Din S, Ubaid F, Shahani E, Saleh F. Reasons for disclosure of gender to pregnant women during prenatal ultrasonography. Int J Womens Health. 2013;5:781-5. https://doi.org/10.2147/IJWH.S40685.

45. Mensah YB, Nkyekyer K, Mensah K. The Ghanaian woman's experience and perception of ultrasound use in antenatal care. Ghana Med J. 2014;48:31. https://doi.org/10.4314/gmj.v48i1.5.

46. Chigbu CO, Odugu B, Okezie O. Implications of incorrect determination of fetal sex by ultrasound. Int J Gynaecol Obstet. 2008;100:287-90. https://doi. org/10.1016/j.ijgo.2007.09.021.

47. Buscarini E, Lutz H, Mirk P. Manual of diagnostic ultrasound, volume 2. Geneva: World Health Organization; 2013.

48. Rijken MJ, Gilder ME, Thwin MM, Ladda Kajeechewa HM, Wiladphaingern J, et al. Refugee and migrant women's views of antenatal ultrasound on the Thai Burmese border: a mixed methods study. PLoS One. 2012;7:e34018. https://doi.org/10.1371/journal.pone.0034018.

49. Firth ER, Mlay P, Walker R, Sill PR. Pregnant women's beliefs, expectations and experiences of antenatal ultrasound in northern Tanzania. Afr J Reprod Health. 2011;15:91-107.

50. Oluoch DA, Mwangome N, Kemp B, Seale AC, Koech A, et al. You cannot know if it's a baby or not a baby': uptake, provision and perceptions of antenatal care and routine antenatal ultrasound scanning in rural Kenya. BMC Pregnancy Childbirth. 2015;15:127. https://doi.org/10.1186/s12884-015-0565-5.

51. Ugwu AC, Udoh BE, Eze JC, Eze PC. Awareness of information, expectations and experiences among women for obstetric sonography in a south East Nigeria population. East Afr J Public Health. 2011;8:132-4.

52. Kozuki N, Mullany LC, Khatry SK, Ghimire RK, Paudel S, et al. Accuracy of home-based Ultrasonographic diagnosis of obstetric risk factors by primarylevel health Care Workers in Rural Nepal. Obstet Gynecol. 2016;128:604-12. https://doi.org/10.1097/AOG.0000000000001558.

53. Blaivas M, Kuhn W, Reynolds B, Brannam L. Change in differential diagnosis and patient management with the use of portable ultrasound in a remote setting. Wilderness Environ Med. 2005;16:38-41. 
54. Roberts T, Henderson J, Mugford M, Bricker L, Neilson J, et al. Antenatal ultrasound screening for fetal abnormalities: a systematic review of studies of cost and cost effectiveness. BJOG. 2002;109:44-56.

55. Swanson D, Lokangaka A, Bauserman M, Swanson J, Nathan RO, et al. Challenges of implementing antenatal ultrasound screening in a rural study site: a case study from the Democratic Republic of the Congo. Global health, science and practice. 2017;5:315-24. https://doi.org/10.9745/GHSP-D-16-00191.

56. Papp Z, Fekete T. The evolving role of ultrasound in obstetrics/gynecology practice. Int J Gynecol Obstet. 2003;82:339-46.

57. Hofmeyr GJ. Routine ultrasound examination in early pregnancy: is it worthwhile in low-income countries? Ultrasound Obstet Gynecol. 2009;34: 367-70. https://doi.org/10.1002/uog.7352.

58. W H O. WHO recommendations on antenatal Care for a Positive Pregnancy Experience: ultrasound examination. Geneva: World Health Organization; 2018.

59. Henwood PC, Mackenzie DC, Rempell JS, Murray AF, Leo MM, et al. A practical guide to self-sustaining point-of-care ultrasound education programs in resource-limited settings. Ann Emerg Med. 2014;64:277-285.e2. https://doi.org/10.1016/j.annemergmed.2014.04.013.

60. Shah S, Bellows BA, Adedipe AA, Totten JE, Backlund BH, et al. Perceived barriers in the use of ultrasound in developing countries. Crit Ultrasound J. 2015;7:28. https://doi.org/10.1 186/s13089-015-0028-2.

61. Kawooya MG, Goldberg BB, De Groot W, Matovu PD, Malwadde EK, et al. Evaluation of US training for the past 6 years at ECUREl, the world Federation for Ultrasound in medicine and biology (WFUMB) Centre of Excellence, Kampala, Uganda. Acad Radiol. 2010;17:392-8. https://doi.org/10. 1016/j.acra.2009.10.009

62. Bagayoko CO, Traoré $\mathrm{D}$, Thevoz $\mathrm{L}$, Diabaté $\mathrm{S}$, Pecoul $\mathrm{D}$, et al. Medical and economic benefits of telehealth in low- and middle-income countries: results of a study in four district hospitals in Mali. BMC Health Serv Res. 2014;14(Suppl 1):S9. https://doi.org/10.1186/1472-6963-14-S1-S9.

63. Mindel S. Role of imager in developing world. Lancet. 1997;350:426-9. https://doi.org/10.1016/S0140-6736(97)03340-0.

64. Maru DS, Schwarz R, Jason A, Basu S, Sharma A, et al. Turning a blind eye: the mobilization of radiology services in resource-poor regions. Glob Health. 2010;6:18. https://doi.org/10.1186/1744-8603-6-18.

Ready to submit your research? Choose BMC and benefit from:

- fast, convenient online submission

- thorough peer review by experienced researchers in your field

- rapid publication on acceptance

- support for research data, including large and complex data types

- gold Open Access which fosters wider collaboration and increased citations

- maximum visibility for your research: over $100 \mathrm{M}$ website views per year

At $\mathrm{BMC}$, research is always in progress.

Learn more biomedcentral.com/submissions 